October 2002 - NREL/TP-510-32206

\title{
Issues Associated with the Use of Higher Ethanol Blends (E17-E24)
}

C. Hammel-Smith, J. Fang, M. Powders, and J. Aabakken

\section{National Renewable Energy Laboratory}

1617 Cole Boulevard

Golden, Colorado 80401-3393

NREL is a U.S. Department of Energy Laboratory

Operated by Midwest Research Institute • Battelle • Bechtel

Contract No. DE-AC36-99-G010337 
October 2002 - NREL/TP-510-32206

\section{Issues Associated with the Use of Higher Ethanol Blends (E17-E24)}

C. Hammel-Smith, J. Fang, M. Powders, and J. Aabakken

Prepared under Task No. BFP2.A101

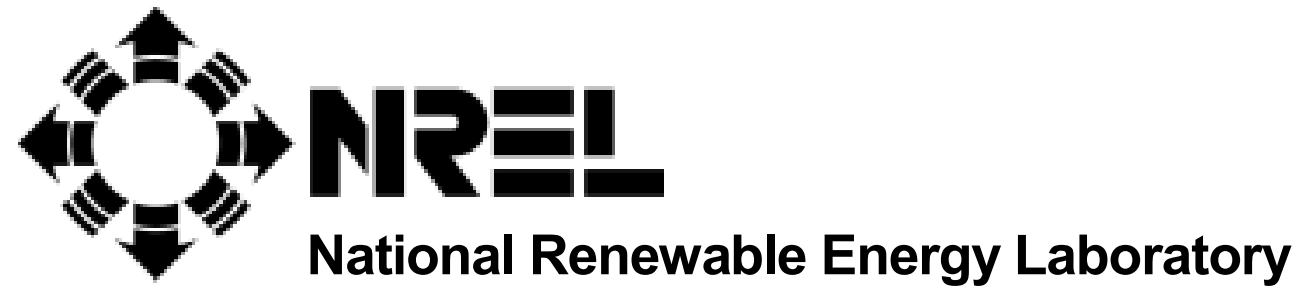

1617 Cole Boulevard

Golden, Colorado 80401-3393

NREL is a U.S. Department of Energy Laboratory

Operated by Midwest Research Institute $\bullet$ Battelle $\bullet$ Bechtel

Contract No. DE-AC36-99-G010337 


\section{NOTICE}

This report was prepared as an account of work sponsored by an agency of the United States government. Neither the United States government nor any agency thereof, nor any of their employees, makes any warranty, express or implied, or assumes any legal liability or responsibility for the accuracy, completeness, or usefulness of any information, apparatus, product, or process disclosed, or represents that its use would not infringe privately owned rights. Reference herein to any specific commercial product, process, or service by trade name, trademark, manufacturer, or otherwise does not necessarily constitute or imply its endorsement, recommendation, or favoring by the United States government or any agency thereof. The views and opinions of authors expressed herein do not necessarily state or reflect those of the United States government or any agency thereof.

Available electronically at http://www.osti.gov/bridge

Available for a processing fee to U.S. Department of Energy

and its contractors, in paper, from:

U.S. Department of Energy

Office of Scientific and Technical Information

P.O. Box 62

Oak Ridge, TN 37831-0062

phone: 865.576.8401

fax: 865.576.5728

email: reports@adonis.osti.gov

Available for sale to the public, in paper, from:

U.S. Department of Commerce

National Technical Information Service

5285 Port Royal Road

Springfield, VA 22161

phone: 800.553.6847

fax: 703.605.6900

email: orders@ntis.fedworld.gov

online ordering: http://www.ntis.gov/ordering.htm 


\section{Executive Summary}

This report reviews the issues associated with utilizing higher ethanol blends (E17-E24), and is intended to advise the Department of Energy (DOE) on factors that might encourage or constrain the integration of such blends into the marketplace. Subjects include technical vehicle issues, emissions and emissions testing, infrastructure, market issues, and regulatory and policy considerations. These subjects are examined in relation to both the changes needed to accommodate higher ethanol blends and the effect of higher ethanol blends on current systems. A full account of the key issues and conclusions and recommendations pertaining to blends in general (ranging from E10-E85), are presented in the Summary, Conclusions, and Recommendations sections. The purpose of this Executive Summary, however, is to focus on key conclusions related to the use of higher ethanol blends. The following are the key conclusions reached in this report.

\section{Technical Issues}

(1) Whether or not higher ethanol blends can be used in conventional vehicles without modification is a central question. The age of the vehicle, the vehicle manufacturer, and its emission control system type are highly important variables (Gardiner 1999).

(2) One of the key issues is the fuel control system's ability to compensate for the higher oxygen content in higher ethanol blends. Some experts assume that higher ethanol blends could fall within a "band of adjustment" accounted for in the fuel control system calibrations. (Gardiner 1999). This line of reasoning is substantiated by the use, in some cases, of the same fuel control sensor in both dedicated gasoline vehicles and in E85 (85\% ethanol) flex-fueled vehicles (Huff 2001).

(3) Availability of the full authority range of the emission control system is an important factor-one which can decrease through normal gasoline operation as the vehicle ages. A Technology Class 5 vehicle, ${ }^{1}$ or one with a vehicle age of five years or less, and an approximate mileage of 60 to 70,000 miles, would likely have more available range than would an older vehicle. ${ }^{2}$ This available range could help to accommodate the use of higher ethanol blends.

(4) In a series of independent tests, E20 blends did not appear to adversely affect fuel control system operation - stoichiometric conditions ${ }^{3}$ were achieved despite the additional oxygen present. However, other sources indicate that current calibrations approximate 4 weight percent (wt. \%) oxygen, whereas 17 volume percent (vol. \%) ethanol would approximate 6 wt. \% oxygen (Reynolds 1999).

\footnotetext{
${ }^{1}$ See Gasoline Using the California Predictive Model, Amended April 25, 2001, page 10. http://www.arb.ca.gov/cbg/premodel/carfg3pm.doc.

${ }^{2}$ Based on telephone discussions with Shean Huff (Oak Ridge National Laboratory, February 22, 2002) and David Gardiner (Nexum Research Corporation, June 24, 1999) concerning the effects of mileage and vehicle age on fuel control system operation.

${ }^{3}$ The perfect balance of air and fuel for any given fuel.
} 
(4) Based on Brazilian experience, it is likely that conventional gasoline catalysts can be used with higher ethanol blends. In recent years, catalyst formulations for $10 \%$ and neat $(100 \%)$ ethanol vehicles in Brazil have been standardized to be similar to those in the U.S. market, indicating that conventional catalysts used in U.S vehicles could also operate on similar ethanol configurations (Szwarc 1999).

(5) Higher ethanol blends will have a positive effect on catalytic efficiency due to the dilution of sulfur. As increased amounts of ethanol are added, catalyst efficiency is improved from 75\%$85 \%$ efficiency to $98 \%-99 \%$ efficiency (Barnes 1999).

\section{Emissions and Emissions Testing}

(6) Emissions data show that volatility decreases in higher ethanol blends (Guerrieri, Caffrey, \& Rao 1995). The volatility curve from gasoline/ethanol blends shows that the highest volatility point is around 5 vol. \% ethanol (API 2001, p. 23). Reid vapor pressure (RVP) increases with low ethanol percentage, but falls again at higher ethanol percentages. E100 actually has a lower RVP than most gasoline blends.

(7) The blending qualities of higher ethanol blends have not been fully explored, and could be beneficial, particularly under California Phase 3 requirements that provide advantages for low RVP and sulfur formulations.

(8) Phase 3 requirements in California could prompt the production of base fuels that are significantly lower in sulfur, which could in turn lower the $\mathrm{NO}_{\mathrm{x}}$ emissions from the base fuel portion of a higher ethanol blend. ${ }^{4}$ Such a $\mathrm{NO}_{\mathrm{x}}$ reduction would not have been characteristic in California Phase 1 or 2, or Federal Phase II gasoline blendstocks. Even though Guerrieri ${ }^{5}$ data show an increase in $\mathrm{NO}_{\mathrm{x}}$ from tests of nine gasoline/ethanol blends ranging from 10 to $40 \mathrm{vol} . \%$ ethanol, it is not known how Phase 3 base fuels could influence $\mathrm{NO}_{\mathrm{x}}$ emission levels without further analysis.

(9) Carbon monoxide (CO) emissions are typically lowered in ethanol-blended fuels. (Myron 1985; CARB 1997; Guerrieri 1995; Faiz 1996). This could, in turn, lower the rate of ozone formation in the atmosphere (National Research Council 1999). In addition, Guerrieri found a significant relationship in blends ranging from $10 \%-40 \%$ ethanol of both total hydrocarbons (THC) and organic matter hydrocarbon equivalent emissions (OMHCE).

\section{Infrastructure Issues}

(10) Higher ethanol blends may be more conducive to pipeline shipment than other blends, particularly in warm temperatures. A 1981 pipeline study conducted by Williams Transportation

\footnotetext{
${ }^{4}$ Automotive Alliance data showing $\mathrm{NO}_{\mathrm{x}}$ reductions in lower sulfur fuels are seen in http://www.arb.ca.gov/cbg/meeting/2001/AlliancePrestn.pdf, and the trend of NOx emission reductions in low sulfur Phase 3 gasoline is discussed in Refining Industry Preparation for California CBG, September 2001, pg. 6.

${ }^{5}$ Guerrieri, DA., Caffrey, J. , \& Rao, V., Investigation into the Vehicle Exhaust Emissions of High Percentage Ethanol Blend. SAE paper \#950777, 1995.
} 
and Terminals found that ethanol could be transported using existing pipelines systems, and that a $10 \%$ blend can tolerate almost twice as much water as a $5 \%$ blend before it separates. The study also found that ethanol blends were more likely to separate in colder temperatures.

(11) To facilitate distribution of ethanol in significant quantities to markets in California, intrastate pipeline shipment in California will play a role (Graboski, Reynolds; Refining Preparation for California CBG3, 2001).

(12) Some of the modifications needed to produce and distribute ethanol blends have been, or are currently being made, to accommodate increased ethanol use since the MTBE phaseout began.

(13) Separate tankage for ethanol storage is already established at E85 fueling stations. Separate handling and storage for E17-E24 would be avoided by blending at the pump for E10, E25, or E85. Existing infrastructure would thus be used to its greatest benefit.

(14) Multi-blend dispensing pumps are used commercially in Sweden. Test trials at E85 stations using these pumps could introduce their use in the United States. Currently, there are about 200 E85 fueling facilities in the United States. ${ }^{6}$

\section{Regional Market Issues}

(15) Based on estimates calculated by the California Energy Commission, total U.S. demand could range from 2.96BGY to 4.02 BGY in the 2003-2004 time period to satisfy all uses of ethanol. If the expected capacity increase takes place as planned, production of fuel markets by 2005 would approximate 4.0 BGY. In the high demand case, supply would be about even with demand; in the low demand case, there would be an excess supply of about 1 BGY.

(16) It is premature to project available ethanol supply for other uses in view of the uncertainties related to expanding ethanol capacity, and of the MTBE-replacement market. However, as the remaining technical questions about using ethanol blends in conventional vehicles are addressed further with respect to the use of higher ethanol blends in conventional vehicles, and if a new EPA waiver can be obtained, higher ethanol blends could represent an additional fuel market, particularly in ozone-attainment areas were volatility is not highly critical, and where E10 is currently used in gasohol, wintertime oxygenated fuel, and octane-enhancer markets.

(17) The use of higher ethanol blends could be seen as a way to extend the gasoline supply as the MTBE phase out deadline (December 2002) approaches. Conversely, higher ethanol blends could absorb excess ethanol in the event that oversupply materializes in the fuel ethanol market. ${ }^{7}$

\footnotetext{
${ }^{6}$ Data on E85 stations provided in peer review comment, Bob Reynolds, Downstream Alternatives, 4-1-02.

${ }^{7}$ Based on discussions with Mike McCormack on March 8, 2002, California Energy Commission. The CEC has also articulated that Flex-Fueled Vehicles offer the same opportunity.
} 


\section{Regulatory and Policy Issues}

(18) Section 211 (f) of the Clean Air Act Amendments of 1977 require that all fuels or fuel additives are "substantially similar" to gasoline used by the Environmental Protection Agency (EPA) as a certification fuel. Any fuel or fuel additive containing more than $2.7 \mathrm{wt} . \%$ oxygen is not considered to be "substantially similar" unless a waiver is obtained from EPA.

(19) Currently, a waiver limits ethanol concentrations to 10 vol. \% (3.5 wt. \% oxygen) in gasoline. Commercialization of higher ethanol blends will require a new waiver.

(20) Expansion of the Federal Excise Tax (FET) Exemption to higher ethanol blends is necessary to correct the tax disadvantage associated with potential blending at higher ethanol levels.

Currently, the statute limits the tax exemption to ethanol blends of no more than 10 vol. \%, prorated levels of $2.0 \mathrm{wt}$. $\%$ oxygen $(5.7 \mathrm{vol} . \%$ ethanol), or $2.7 \mathrm{wt}$. $\%$ oxygen $(7.7 \mathrm{vol} . \%$ ethanol). When the FET exemption cannot be claimed, blenders have no option other than to rely on the Blenders Tax Credit. However, in many cases, blenders do not have sufficient tax liability to utilize the credit to full advantage. 


\section{Acronyms and Abbreviations}

AFV

ALA

AMT

API

BGY

BTC

btu

CAAA

CARB

CEC

$\mathrm{CO}$

$\mathrm{CO}_{2}$

CRC

DIPE

DOE

E

EIA

EPA

EPAct

ETBE

FET

FFV

FTP

GEG

GHG

$\mathrm{HC}$

LEV

MGY

MIR

MON

MPD

MTBE

MVEI

NGCA

NMOG

$\mathrm{NO}_{\mathrm{x}}$

NREL

OBD

OFP

OMHCE

PCM

RBOB

RFA

RFG

alternative fuel vehicle

American Lung Association

alternative minimum tax

American Petroleum Institute

billion gallons per year

blenders tax credit

British Thermal Unit

Clean Air Act Amendments of 1990

California Air Resources Board

California Energy Commission

carbon monoxide

carbon dioxide

Coordinating Research Council

di-iso-propyl ether

U.S. Department of Energy

ethanol

Energy Information Administration

U.S. Environmental Protection Agency

Energy Policy Act of 1992

ethyl tertiary butyl ether

federal excise tax

flex-fueled vehicle

federal test procedure

gasoline equivalent gallons

greenhouse gas

hydrocarbon

low emission vehicle

million gallons per year

maximum incremental reactivity

motor octane number

multi product dispensing

methyl tertiary butyl ether

motor vehicle emissions inventory

National Corn Growers Association

non-methane organic gases

nitrogen oxides

National Renewable Energy Laboratory

on-board diagnostics

ozone forming potential

organic matter hydrocarbon equivalent

power train control module

refinery blendstock for oxygen blending

Renewable Fuels Association

reformulated gasoline 
RON

RVP

SAI

SR

TAME

TBA

THC

TOX

UAM

ULEV

VOC

vol. $\%$

wt. $\%$ research octane number

Reid Vapor Pressure

Systems Applications International

specific reactivity

tertiary amyl methyl ether

tertiary butyl alcohol

total hydrocarbons

toxic masses

urban airshed modeling

ultra-low emission vehicle

volatile organic compound

volume percent

weight percent 


\section{Table of Contents}

Executive Summary ___ i

Acronyms and Abbreviations __ $v$

Table of Contents __ vii

List of Figures __ viii

List of Tables__ v viii

I. Introduction __ 1

II. Technical Issues __ 3

Background __ 3

Fuel Control System _ 3

Air/Fuel Ratio $\longrightarrow 4$

Oxygen Sensor_ 5

Fuel Quality __ 6

Driveability _ 6

Hot Operation _ 6

Cold Start-Up__ 7

Enleanment 7

Materials Compatibility___ 8

On-Board Diagnostics __ 9

Technical "Lessons Learned" from the Brazilian Experience __ 9

III. Emissions and Emissions Testing ___ 11

Higher Ethanol Blends and RVP

The Function of Base Fuel in Counteracting Higher Volatility____ 13

Other Emissions Testing__ 16

Brazilian Emissions Data___ 19

IV. Infrastructure Issues _ 21

Distribution Infrastructure __ 21

Ethanol-Blend On-Site Storage and Blending__ 22

Pipeline Shipment _ 23

Pipeline Shipment of Higher Ethanol Blends __ 26

V. Ethanol Market Issues___ 29

Background _ 29

U.S. Production — 29

California Demand __ 30

Other Demand __ 32

Implications for Higher Ethanol Blends __ 32

VI. Regulatory and Policy Issues___ 35

Substantially Similar Fuels__ 35 
Regulatory Approval for Higher Ethanol Blends 36

Replacement Fuels Requirements __ 36

Federal Excise Tax and Blenders Tax Credit___ 37

VII. Summary, Conclusions and Recommendations __ 39

References __ 43

Appendix A Technical Issues___ A-1

Appendix B Emissions and Emissions Testing___ B-1

Appendix C Regulatory and Policy Issues ___ C-1

\section{List of Figures}

3-1 Effect of Oxygenate Concentration on Blend Vapor Pressure 12

4-1 Flexible Infrastructure for the Future 22

4-2 Ethanol Plants and Existing Petroleum Pipelines 25

5-1 Federal RFG Areas in California 31

\section{List of Tables}

2-1 Vehicle Technology Groups 4

3-1 Relationship Between RVP and Vol. \% Ethanol of Test Fuels 13

3-2 Blending RVP Case Studies 14

3-3 EPA Unit Risk Factors for Air Toxic Emissions 18

3-4 Relative Emissions in Brazil's Ethanol Fuel Program ___ 19

4-1 Infrastructure Modifications 22

7-1 Key Conclusions, Open Issues, and Recommendations 40-42

B-1 Composition of Test Fuels in CARB's High RVP $10 \%$ Ethanol Blend Study B-4

B-2 Percent Change in Emissions of Elevated RVP Ethanol Blend Compared to Complying Blend B-6 


\section{Introduction}

The National Renewable Energy Laboratory (NREL) supports the U.S. Department of Energy (DOE) in assessing the implications of increasing the volume amounts of ethanol in gasoline blends. The purpose of this report is to identify issues associated with using higher ethanol blends, (17-24 volume percent (vol. \%), or E17-E24), and to serve as a reference resource for DOE on factors that would influence integrating higher ethanol blends into the existing automotive fleet and supporting infrastructure. Higher ethanol blends ${ }^{8}$ were chosen for study for the following reasons:

(1) Blends in this range may provide a mechanism to introduce greater amounts of ethanol into the marketplace, which would in turn support the DOE's energy security mission to reduce U.S. oil imports;

(2) Emissions data indicate that blends ranging from 17-24 vol. \% ethanol would result in greater reductions in carbon monoxide, total hydrocarbons, and be less volatile than blends ranging from 5.7-10 vol. \% ethanol (Guerrieri 1995; Faiz 1996).

The report is divided into technical, emissions, infrastructure, market issues, and regulatory policy sections. Within each section the report reviews the major points of each issue, and highlights where divergence of opinion exists among experts. The report also indicates where future analysis may be warranted.

Technical Issues - reviews the effects of higher ethanol blends on conventional vehicles and fuel control systems, conventional catalysts, driveability, fuel quality, and materials compatibility.

Emissions and Emissions Testing - discusses available emissions testing data on E17 - E24, and the relationship between Reid vapor pressure (RVP) and increasing ethanol concentration in blends, Brazilian emission data, and the impact of Phase 3 low sulfur and RVP requirements in California.

Infrastructure Issues - highlights data concerning pipeline transport of neat ethanol and ethanol blends, reviews infrastructure developments in California as methyl tertiary butyl ether (MTBE) is being phased out, and looks at multiple product blending at the pump as a way to introduce E17E24 on a limited basis at E85 fueling stations. Existing tankage could be fully utilized while paving the way for various blends to be tested.

Market Issues - presents an estimate calculated by the California Energy Commission (CEC) of total U.S. ethanol demand. The range is between 2.96 BGY and 4.02 BGY in the 2003-2004 time period to satisfy all uses of ethanol. If the expected capacity increase takes place as planned, production of fuel markets by 2005 would approximate 4.0 BGY. In the high demand case,

\footnotetext{
${ }^{8}$ For the purposes of this report, blends ranging from 17-24 vol. \% ethanol are referred to as "higher ethanol blends" because they contain greater amounts of ethanol compared to gasoline blends currently in the marketplace ranging from 5.7- 10 vol. \% ethanol. E17 - E24 blends would be regulated as "gasoline blends" under Clean Air Act Amendments of 1990 provisions found in 40 CFR Part 80, Regulation of Fuels and Fuel Additives; Definition of Substantially Similar. In contrast, fuels containing a minimum of 85 vol. \% ethanol are defined as "alternative fuels," under both Clean Air Act Amendments of 1990 and Energy Policy Act provisions of 1992. (See 40 CFR Part 80, Section 241 (1), and Section 301 (2), respectively.)
} 
supply would be about even with demand; in the low demand case, about 1 BGY excess supply would exist.

Regulatory and Policy Issues-reviews the Environmental Protection Agency's (EPA) "substantially similar" provisions and the need for a new waiver for E17-E24. The chapter also reviews the implications of the Federal Excise Tax and the Blenders' Tax Credit with respect to the use of E17-E24.

\section{Areas for Further Analysis}

The report identifies four areas where additional effort would be required to fully address the most significant issues.

(1) A follow-on report would be useful to document the Brazilian experience in greater detail. Information on emissions data and infrastructure could be significantly expanded.

(2) Whether or not higher ethanol blends can be used in conventional vehicle systems without deleterious effects on emissions, driveability, or materials compatibility is a central question. The report highlights factors that affect whether or not higher ethanol blends can be used in a conventional, non-modified, vehicle. However, definitive conclusions require testing in all vehicle classes and technology groups to confirm or refute the effects of higher ethanol blends. Extensive testing on a vehicle-to-vehicle basis would provide vehicle manufacturers with valuable information pertaining to potential warranty coverage. ${ }^{9}$

(3) A comprehensive analysis of fuel economy was beyond the scope of this report, but remains an important issue that should be further assessed. Fuel economy estimates assume a reduction in energy content of approximately $8 \%$ compared to unblended gasoline, ${ }^{10}$ which may or may not be acceptable to consumers.

\footnotetext{
${ }^{9}$ Reynolds, peer review comment, November 20, 2001.

${ }^{10}$ Based on the assumption that a $24 \%$ blend would contain approximately 105,600 British Thermal Units (btus) vs. 115,000 btus for gasoline. Data provided in peer review comments by Bob Reynolds, Downstream Alternatives, November 20, 2001.
} 


\section{Technical Issues}

This section will focus on technical issues related to vehicles using higher ethanol blends, (E17 E24). These issues fall into two basic categories: (1) conventional fuel control systems (see Appendix A for comparative discussion on E85 systems) and (2) driveability. The fuel control system section will include discussions on the importance of the oxygen sensor and maintaining the proper air/fuel ratio. The driveability section will review hot operation, cold-start, enleanment, on-board diagnostics (OBD), and materials compatibility issues, including impacts on polymers and engine operation. Finally, the chapter reviews the technical adaptations made to Brazilian vehicles for use with both neat and E24 vehicles.

\section{Background}

The issue of whether higher ethanol blends can successfully be used in conventional vehicles is key to their expanded deployment. However, there are divergent expert opinions on whether E17-E24 could detrimentally affect fuel control system operation and materials in a conventional vehicle. This section does not attempt to resolve the controversy, but rather presents the current views of experts and their findings. Attaining a definitive answer will require further study.

Little specific testing has been completed on higher ethanol blends. Rather, the testing has focused either on E85 (intermediary points were not assessed in flex-fueled vehicle [FFV] testing) (Rhoad 1999) or on 10\% ethanol blends. Under contract to NREL, the Nexum Research Corporation of Ontario, Canada, conducted a fuel efficiency and emissions analysis on E20, E40, and E85 blends. Blends of 15\% were also considered in the late 1970s. Although Brazil has had an extensive blended fuel program, vehicle systems in Brazil were initially optimized for neat fuels. Due to this prior optimization, impacts on existing (e.g., conventional) fuel systems were not extensively observed when blends ranging from E22 -E24 became widely used.

Therefore, without additional testing, it is difficult to say with absolute certainty what the effects of higher ethanol blends will be on emissions, driveability, and material compatibility. Some air pollution and automotive specialists choose to err on the side of conservatism and assume that effects occurring with E85 fuels could also occur to some degree with other ethanol blends (Livo 99). However, other experts postulate that higher ethanol blend effects could be limited (Gardiner 1999).

\section{Fuel Control System}

The fuel control system is critical to the normal operation and emission control of the vehicle. It is also sensitive to changes in fuel composition. For higher blends of ethanol to work well in conventional vehicles, the fuel control system must be able to compensate for differences between ethanol blends and gasoline (due predominantly to ethanol's higher oxygen content).

Fuel control systems vary considerably depending on the year the vehicle was manufactured. The California Air Resources Board (CARB) defines three vehicle technology groups associated with specific emission control equipment. Table 2-1 shows that Technology Class 3 is the oldest vehicle group (1981-1985), with the least sophisticated emission controls. Technology Class 3 has an older version of closed-loop, three-way catalyst technology. Technology Class 4 includes 
vehicles manufactured between 1986-1995 and is characterized by more advanced closed-loop, three-way catalyst emission control technology. Technology Class 5 vehicles were manufactured in 1996 or later, and are categorized as low emission vehicles (LEVs) with three-way catalysts and adaptive learning.

Table 2-1

Vehicle Technology Groups

\begin{tabular}{|l|l|l|}
\hline Technology Class & Model Year & Emission Controls \\
\hline Tech 3 & $1981-1985$ & older closed-loop three-way catalyst \\
\hline Tech 4 & $1986-1995$ & closed-loop three-way catalyst \\
\hline Tech 5 & $1996+$ & three-way catalyst, adaptive learning, LEVs \\
\hline
\end{tabular}

Source: California Air Resources Board, $2001^{11}$

Availability of the full authority range of the emission control system is an important factor when considering the use of higher ethanol blends. Authority range can decrease through normal gasoline operation as the vehicle ages. A Technology Class 5 vehicle, or one with a vehicle age of five years or less and an approximate mileage of between 60,000 and 70,000 miles, would likely have more available range than would an older vehicle. ${ }^{12}$

\section{Air/Fuel Ratio}

Due to greater availability of range authority and to advanced emission control technology it is possible that the fuel control systems on Technology Class 5 vehicles could compensate for higher ethanol blends by re-calibrating the air/fuel ratio settings accordingly. These vehicles are equipped with superior "block learning capabilities" with the ability to adapt the base fuel control settings to accommodate the higher oxygen levels. A key point is that the adaptation process must occur in the closed loop phase of the vehicle operation, i.e., hot operation. Adaptive learning does not take place in the open loop, or transient, start-up phase. It is also important to note that systems may vary among vehicle manufacturers. Although each is striving toward a common goal, algorithms in fuel control systems are considered to be highly proprietary, and consequently, may produce different results (Gardiner 1999).

In contrast, however, automakers state that narrow oxygen parameters are necessary in the fuel control system settings to meet the increasingly strict vehicular air quality standards of both California LEV II and Federal Tier 2. Both California LEV II and Federal Tier 2 begin phase-in requirements in 2004. Further, ultra low emission vehicle (ULEV) and European Union Stage $3 / 4$ technologies can be better optimized when the fuel control system calibrations are confined

\footnotetext{
${ }^{11}$ Information derived from California Procedures Evaluating Alternative Specifications for Phase 3 Reformulated Gasoline Using the California Predictive Model, Amended April 25, 2001, page 10. http://www.arb.ca.gov/cbg/premodel/carfg3pm.doc

${ }^{12}$ Based on telephone discussions with Shean Huff (Oak Ridge National Laboratory, February 22, 2002) and David Gardiner (Nexum Research Corporation, June 24, 1999) concerning the effects of mileage and vehicle age on fuel control system operation.
} 
to narrower ranges (Barnes, Beard, Rhoad 1998-1999). In addition to meeting emission requirements, automakers also maintain that narrow oxygen parameters would minimize changes needed on advanced vehicles.

\section{Oxygen Sensor}

An integral component of the fuel control system is the oxygen sensor, which is located in the exhaust stream. The higher the oxygen content in the exhaust, the greater the voltage transmitted from the oxygen sensor to the computer.

Despite the differences in oxygen levels, current practice in the automotive industry is to use the same oxygen sensor in both dedicated gasoline vehicles and E85 flex fuel vehicles (FFVs); with negligible impacts on system operation (Huff 2001, Gardiner 1999). Further, the results of tests conducted for NREL (by Nexum Research Corporation) on E20 blends utilizing a standard oxygen sensor, indicate that standard oxygen sensors operate effectively in an E17-E24 environment. Stoichiometric conditions were achieved despite the additional oxygen present.

However, an opposing view suggests that the oxygen sensor and its interaction with the power train control module (PCM) has a limited authority range of about $4 \%$ oxygen, and can therefore not properly calibrate for a $17 \%$ ethanol blend which approaches $6 \%$ oxygen (Reynolds 1999). In certain vehicles, the oxygen sensor could have a limited ability to transmit voltage, and could be unable to transmit voltage levels commensurate with the level of oxygen present in the fuel (Cagle 1999).

$\mathrm{NO}_{\mathrm{x}}$ emissions may be elevated due to the PCM's inability to compensate for higher oxygen levels. The argument further maintains that ULEVs and other future technology vehicles will require an air/fuel trim within a very tight range to achieve emissions compliance. Experts in the field maintain that automakers prefer oxygen levels no higher than $2 \mathrm{wt}$. \% so that a tighter range can be maintained (Reynolds, 1999). However, $\mathrm{NO}_{\mathrm{x}}$ levels may also be reduced, independently of the fuel control system equipment, due to the reduced combustion temperatures of ethanol blends. In addition, if increases in $\mathrm{NO}_{\mathrm{x}}$ are noted, the oxygen sensor can be used to compensate for the increased oxygen level (Huff 2001). 


\section{Fuel Quality}

The effect of wider oxygen parameters on a tightly controlled air/fuel ratio relates to the broader issue of fuel quality. Automakers are focusing considerable attention on narrowing fuel specifications wherever possible. Proposed petitions would confirm the T-50 specification at $170^{\circ}\left(50 \%\right.$ of the fuel evaporates at $\left.170^{\circ}\right)$, and eliminate the one psi RVP variance for ethanol blends. (As provided for in 87 CFR 80, for conventional fuels only.) Because RVP measures how easily a liquid evaporates, a higher RVP means that more of the fuel can evaporatecontributing to the formation of ground-level ozone. To limit the possibility of such emissions, EPA has set progressively tighter limits on RVP in fuels.

Because it is difficult for ethanol blends to meet the $170^{\circ} \mathrm{T}-50$ specification, ethanol blenders have traditionally relied on the RVP variance to compete in oxygenated fuel markets. However, the variance may not be necessary for higher ethanol blends since RVP decreases are seen as the volume of ethanol increases. As discussed in the emission section, additional work is needed to further characterize the blending attributes of higher ethanol blends with respect to volatility. Areas of study should include assessing base fuel qualities that would optimize higher ethanol blend use.

Automaker support for developing and maintaining narrow fuel specifications is seen in the proposed WorldWide Fuel Charter. Category Three for Unleaded Gasoline will predominantly serve geographic areas where LEV and ULEV advanced emissions control system technologies will be utilized. Footnotes $4 \mathrm{a}$ and $4 \mathrm{~b}$ in the Charter state that fuel without oxygenates is preferred, but where oxygenates are used, ethers are recommended. The Category 3 specifications also permit an oxygen level of $2.7 \mathrm{wt} \%$.

The current provisions of the Charter discourage the use of ethanol at any blend level, but set an oxygen limit of $2.7 \%$ wt limit. Both of these provisions would require modification to support the use of higher ethanol blends.

\section{Driveability}

Drivers have an expectation of how a vehicle will operate under normal driving conditions. How well a vehicle conforms to this expectation can be defined as driveability. When assessing drivability and the use of ethanol, the following factors are often considered: (1) hot operation; (2) cold-start; (3) enleanment; (4) materials compatibility; and (5) onboard diagnostics.

\section{Hot Operation}

Automakers have voiced concerns about higher ethanol blends impacting hot driveability. The volatility of $5.7 \%-10 \%$ ethanol blends is approximately 1 psi higher than unleaded gasoline unless a low-RVP base fuel is used. Vapor lock, and difficult hot start can potentially occur more often in a fuel with a higher volatility, particularly in summertime conditions. However, in current practice, manufacturers have already engineered solutions to this problem since E10 is so widely used in today's gasoline market (Huff 2001). 
As discussed in detail in the Emissions section, however, test results have shown the RVP increase begins to reverse itself as the percentage of ethanol increases (Guerrieri 1995). Although the point at which the RVP decreases is highly contingent upon the base fuel characteristics, Guerrieri indicates that the RVP will begin decreasing with increased ethanol level around $17 \%-20 \%$ ethanol blend level, and will reach the original RVP of the gasoline alone at about $25 \%$ ethanol blend level. The base fuel in the Guerrieri report was a representative summertime fuel, of regular grade with no measurable amounts of ethanol or oxygen.

Other issues relate to $\mathrm{NO}_{\mathrm{x}}$ and the lower operating temperature of ethanol. $\mathrm{NO}_{\mathrm{x}}$ levels may be reduced due to the reduced combustion temperatures of ethanol blends. ${ }^{13}$ However, although $\mathrm{NO}_{\mathrm{x}}$ levels could be reduced due to reduced combustion temperatures (i.e, a lower T-50 value), concern exists in the auto industry that the lower T-50 could trigger a conventional fuel control system to adjust fuel flow, which could lead to "rich excursions," and increased emissions. ${ }^{14}$

Another potential hot operation drivability issue is water phase separation in the fuel system. However, in fuel injection systems, water phase separation (which can cause engine stalls and other driveability problems) is less likely than it was with carbureted systems (Gardiner 1999). In addition, a strict 1996 evaporative emissions requirement resulted in some, if not all, emission control system designs that circulate the fuel in a small loop near the tank (Huff, 2001). This circulation tends to keep the fuel mixed better and discourages phase separation.

\section{Cold Start-Up}

In E85 vehicles, cold start-up has sometimes been difficult, particularly if the outside temperature is also low. In the vehicle, gasoline was added to the E85 mixture to encourage engine start-up (Barnes 1999). However, cold start-up problems may not be indicated with higher ethanol blends since they will have a much greater percentage of gasoline initially in the fuel mixture as compared to E85, and a higher RVP.

\section{Enleanment}

If a fuel control system is unable to adjust an air/fuel ratio properly because of an excess of oxygen, enleanment ${ }^{15}$ could result; however this is unlikely in vehicles operating on higher ethanol blends since features from E85 vehicles have been incorporated into gasoline vehicles. Common problems when an engine is running very lean are loss of power and engine misfires, which could cause emissions increases.

Another possible effect could be transparent to the driver. No visible signs of lean operation would be prevalent, but the air/fuel mixture would be lean enough to potentially affect the catalytic converter's operation (Cagle 1999). The first section in the catalyst is designed to reduce $\mathrm{NO}_{\mathrm{x}}$. In order for the chamber to operate efficiently, a fuel-rich mixture should be present. If the fuel had become leaner through the introduction of additional ethanol, and if the fuel control system did not effect the appropriate adjustments, the fuel mixture would be leaner than catalyst

\footnotetext{
${ }^{13}$ Huff, peer review comments, December 19, 2001.

${ }^{14}$ Discussion introduced in peer review comments submitted by Bob Reynolds, Downstream Alternatives, October $31,2001$.

${ }^{15}$ Enleanment is characterized by excess oxygen affecting the stoichiometric ratio of the fuel. As mentioned previously, the stoichiometric ratio refers to the "perfect" air/fuel ratio for a given fuel.
} 
requirements. The second chamber, however, designed to operate in lean conditions to neutralize unburned hydrocarbons and $\mathrm{CO}$, would operate effectively.

Information from Brazilian experts (Szwarc 1999) indicates that the catalyst formulations developed for conventional U.S. vehicles will likely work in a higher ethanol blend environment, providing the necessary conditions exist (e.g., temperature). In addition, higher ethanol blends can also have a positive effect on a catalyst's efficiency. As greater amounts of ethanol are added in the ethanol blending process, sulfur is diluted. Because sulfur coats the catalyst and deters its efficiency, air quality standards are requiring lower sulfur parameters. With the addition of increased amounts of ethanol, catalyst efficiency is improved from $75 \%-85 \%$ efficiency to $98 \%$ - 99\% efficiency (Barnes 1999).

\section{Materials Compatibility}

Alcohol fuels have different physical and chemical properties than gasoline, which affects their compatibility with fuel system components. However, using corrosion-inhibiting additives, as well as the chemical composition and physical properties of the base fuel, affect the degree of materials incompatibility.

Discussion published in a report by Oak Ridge National Laboratory (1988) indicates compatibility in fuel system parts with $15 \%$ ethanol blends. Testing conducted at the Technical Research Center of Finland found that vehicles fueled on E15 ran satisfactorily on stock carburetor settings without modification. ${ }^{16}$ In addition, eight out of ten test cars that were fueled on E15 showed less or equal wear compared to the same vehicles operated on gasoline.

In its review of polymer permeability, Oak Ridge notes that Du Pont ${ }^{17}$ found that highly fluorinated fluorohydrocarbons provided the best resistance to either highly aromatic gasoline or to ethanol. In addition, Dunn and Pfisterer ${ }^{18}$ found that permeability issues could be remedied by applying a thin nylon veneer to the outside of nitrile rubber compounds. (Polymer permeability is a concern of automakers, viewed as a major factor in evaporative emissions.)

It is likely that many of these research results have been incorporated in modern vehicle systems. In addition, years of materials testing on alternative and blended fuels have been applied to conventional systems as well. It is estimated that the sophisticated fuel system materials of today's vehicles could likely resist any additional corrosivity associated with higher ethanol blends (Gardiner 1999).

Other potential materials compatibility questions pertain to engine wear observed in E85 vehicles. In the GM Lumina, the cylinder bore showed wear problems, and the piston ring showed evidence of not sealing properly (Barnes 1999). Due to alcohol's superior cleansing ability, the "cylinder wall wash" has been documented in engines where high alcohol concentrations have been used. The "cylinder wall wash" is characterized by a loss of film, or

\footnotetext{
${ }^{16}$ The authors recognize that present-day vehicles are fuel-injected rather than carbureted. However, sufficient similarities exist among the physical characteristics of the materials to allow for reasonable comparison.

${ }^{17}$ See Nersasian, A., (E. I. du Pont de Nemours \& Co., Inc.,) "The Vol. Increase of Fuel Handling Rubbers in Gasoline/Alcohol Blends." SAE Paper No. 800789, June 1980.

${ }^{18}$ See Dunn, J. R., and H. A. Pfisterer (Polystar Limited), "Resistance of NBR-Based Fuel Hose Tube to FuelAlcohol Blends." SAE Paper No. 800856, June 1980.
} 
oil, on the cylinder walls, thereby causing more friction (Livo 1999). Flex-fueled vehicles have therefore required a special lubricant.

However, few, if any incidents have been reported on $10 \%$ blends associated with "cylinder wall wash." Impacts from higher ethanol blends should be further quantified, but would likely be more similar to impacts of E10, rather than of E85.

\section{On-Board Diagnostics}

It is theorized that the "on board diagnostics" (OBD) system could react to higher ethanol blends (Cagle 1991). The computer linked to the OBD system is programmed to fuel specifications within prescribed ranges. Therefore, an oxygen level approximately twice as high as the maximum currently allowed under EPA fuel specifications (i.e., 3.5\% - 3.7\% oxygen by weight vs. $6.8 \%-7.2 \%$ oxygen by weight) could trigger an OBD response. The driver would be alerted by a "check engine light" on the dash, indicating maintenance needed, which would actually constitute a false OBD alert. Although not serious with respect to safety, such a false OBD alert could inconvenience the driver.

\section{Technical “Lessons Learned” from the Brazilian Experience}

The Brazilian government implemented the National Alcohol Program in 1975 to create a large ethanol demand base. Initially, Brazil moved to regulate the nation's gasoline market to decrease dependency on imported oil. In the years following program initiation, ethanol's value developed in two ways - as a volume extender, thus decreasing the amount of crude oil purchases, and as a greenhouse gas (GHG) mitigation strategy. The National Alcohol Program was established by government guarantees to enable broad participation in a nationwide program. These guarantees legally determined that all gasoline sold in the country would be blended with $22 \%$ vol. (now $24 \%$ vol.) anhydrous ethanol, and that the consumer price of hydrous ethanol would be maintained at levels that would create incentive to buy neat ethanol cars. Gasoline blends of $24 \%$ ethanol (gasohol) and neat hydrous ethanol are distributed in every part of Brazil.

As a result of the program, Brazil's three most significant contributions are as follows:

(1) development of automobile technology for the use of neat ethanol and ethanol blends;

(2) development of an ethanol distribution system; and

(3) development of technology to produce hydrous ethanol under very strict specifications, allowing the use of neat ethanol in fuel injection systems (Nastari 1998).

In 1977, the Brazilian Aerospace Technological Center researched the fuel properties of alcohols and gasoline. Nastari (1998) cited the following points:

- Ethanol contains a higher number of molecules after combustion than hydrocarbons thus producing higher compression;

- The higher ethanol anti-knocking characteristic allows higher air-fuel mixture compression and, consequently, better thermal efficiency;

- The higher ethanol tolerance to burn with excess air allows better combustion, producing lower $\mathrm{CO}$ and particle emission levels; 
- The higher ethanol latent heat vaporization increases the engine overall efficiency due to the reduction of heat loss, and reduces the engine tendency to knock;

- The ethanol molecular simplicity reduces carbon formation and flame radiation, which improves internal energy conversion.

The findings from this work established the basis for designing and calibrating an ethanol engine. Engine power and fuel economy were prioritized in the initial design phases, as was the search for materials that would resist ethanol's corrosive nature.

In January 1992, the oxy-catalytic converter and electronic fuel injection was introduced in both the neat ethanol and gasohol engines. An $80 \%$ reduction in emission levels was achieved with both engines, and the neat ethanol engine maintained its $\mathrm{CO}$ and $\mathrm{HC}$ emissions advantage.

Traditional gasoline engine catalytic converters were built with rhodium and platinum. Brazilian automakers designed gasohol engines with catalytic converters based on platinum and palladium, and neat ethanol engine converters based on palladium alone. However, since 1997, catalyst formulations for gasohol and neat ethanol vehicles have been standardized to be similar to those in the U.S. market. Szwarc assumes E17 - E24 blends would in most instances be compatible with conventional vehicle catalysts, providing the necessary conditions exist, including temperature (Szwarc 1999).

The use of electronic mapped digital systems plays an important role in alcohol engine evolution, because these systems control ignition, fuel injection, emissions, automatic transmissions, and other engine components. Advanced research points out that using mapped ignition with piezoelectric knocking sensors improved the compression ratios in ethanol engines, which also improved the thermal efficiency and cold start properties.

As the Brazilian automobile technology continued to develop with the use of neat ethanol and gasohol, fuel specifications and distribution systems have also adapted. Larger oil companies such as Petrobras, Shell, Exxon, and Texaco dominate Brazil's fuel distribution. These companies transport both neat ethanol and gasohol in multipurpose pipelines without pigs, and have stored and distributed ethanol for over 20 years without any major upsets or unresolved problems (Nastari 1998).

The successful deployment of ethanol blends in the U.S. market is dependent not only on conventional vehicle system compatibility but also to a large extent on meeting current and future vehicle emissions standards. This issue is discussed in the next section. 


\section{Emissions and Emissions Testing}

One of the largest potential expanded uses in the near term for ethanol is as an oxygenate in fuel. Oxygenates are added to gasoline to reduce emissions of carbon monoxide (CO) and ozone precursors in designated metropolitan areas of the country. In June, 2001, California's request to the EPA to be granted a fuel additive waiver was denied.

Therefore, oxygenate requirements are in effect in one of the largest regional markets for oxygenates.

Because ethanol is successfully used as an oxygenate in other parts of the country, a significant opportunity for expanded use of ethanol exists in California providing strict volatility controls can be met. (RVP, the measure for volatility, quantifies a liquid's propensity to evaporate into emissions.) One of the promising characteristics of higher ethanol blends is that volatility decreases as the amount of ethanol in a gasoline blend increases. For this reason the role that higher ethanol blends can play in reducing volatility in reformulated gasoline and other oxygenated fuels should be further explored.

This section draws upon limited data pertaining to volatility in ethanol blends, including trends showing reduced volatility as ethanol volume increases. Issues pertaining to the use of specially configured base fuels to counteract higher volatility are discussed and the results of the California Air Resources Board (CARB) Twelve-Vehicle Study are reviewed within that context. (See Appendix B for complete discussion). Finally, other emissions data pertaining to both ethanol blends and E85, including Brazilian emissions data, and the 1999 National Research Council's assessment of CO's impact on ozone formation are examined.

\section{Higher Ethanol Blends and RVP}

\section{Issue: How does the ethanol content in blended gasoline affect the RVP of the gasoline blend?}

Ethanol as a neat alcohol has low RVP relative to methanol, MTBE, and motor gasoline. The RVP for ethanol is 2.3 psi, compared to 4.6 psi for methanol, 7.8 psi for MTBE, and 7 - 15 psi for motor gasoline (American Petroleum Institute [API] 2001, p. 3). However, in some ethanol blends, blending ethanol with gasoline does not lower vapor pressure, but instead causes the blend's RVP to increase. As shown in Figure 3-1, the increase in RVP is highest at about 5 vol. \% ethanol, raising the RVP by a bit over 1 psi from the level of the original 9 psi of the base gasoline.

However, as ethanol content increases, the increase in RVP falls gradually. In a 20 vol. \% blend, the volatility is lower than a 5 vol. \% blend. The volatility decrease continues, as shown in Table 3.1. 


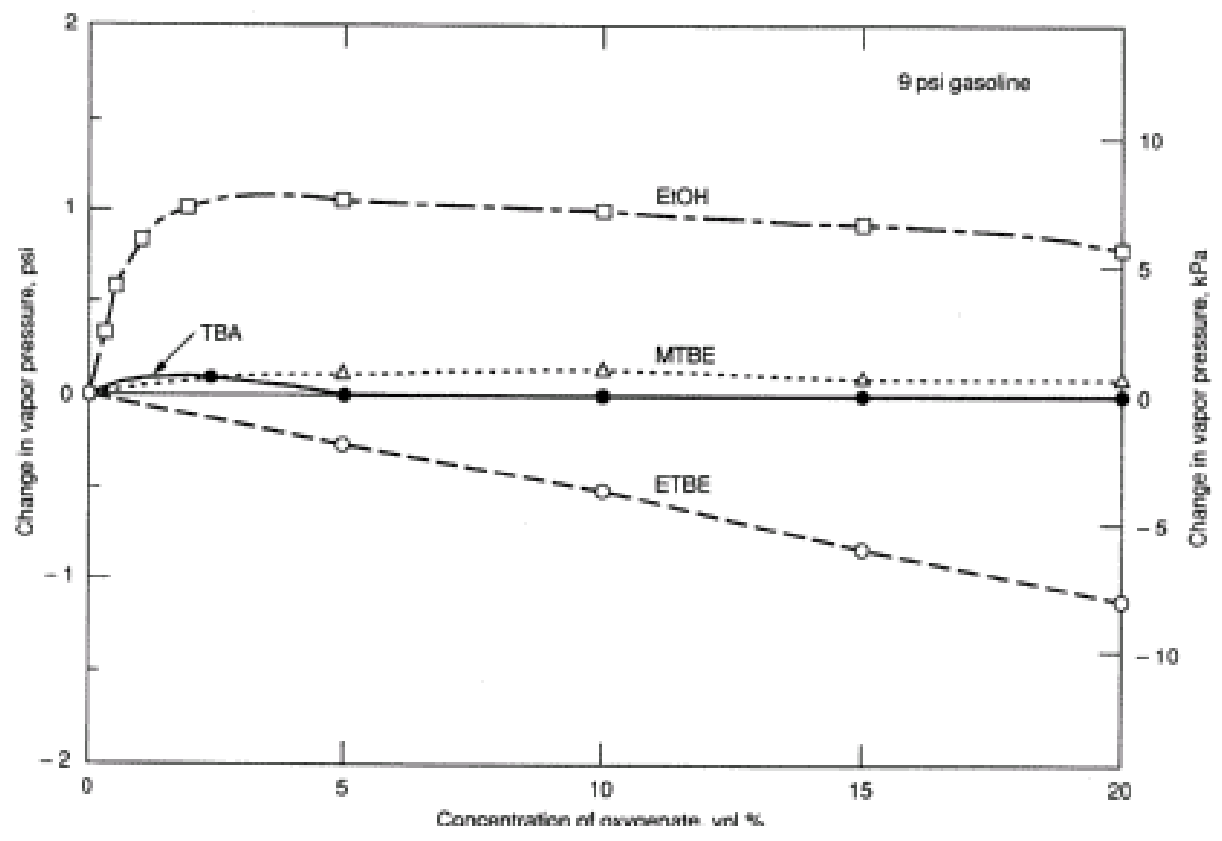

Source: American Petroleum Institute, 2001, p. 23

Figure 3-1 Effect of Oxygenate Concentration on Blend Vapor Pressure

Issue: How robust is the inverse relationship between RVP and ethanol content for ethanol blended fuels? Data show that RVP starts to fall in the range of $14 \%-20 \%$ ethanol by volume, depending on base fuel characteristics.

The study on the exhaust emissions of high percentage ethanol blends by Guerrieri, Caffrey, and Rao (1995) provided additional information on the effects of ethanol content on RVP of the blended gasoline beyond the range of ethanol content given in the API report. Although the authors did not specifically address the relationship between fuel volatility and ethanol content, they did present underlying data on the properties of the test fuels. As shown in Table 3-2, for ethanol content beyond 12 vol. \%, there is a negative relationship between the computed RVP and the ethanol content in the test fuels. Initially, RVP rises from 8.63 psi with $0 \%$ ethanol to 9.28 psi with $12 \%$ ethanol, then falls to 8.3 with $40 \%$ ethanol. 
Table 3-1 Relationship between RVP and Volume Percent Ethanol of Test Fuels

\begin{tabular}{|c|c|c|}
\hline Fuel Number & Vol. \% Ethanol & RVP (Psi) $^{*}$ \\
\hline 1 & 0.0 & 8.63 \\
\hline 2 & 10.0 & 9.15 \\
\hline 3 & 12.0 & 9.28 \\
\hline 4 & 14.0 & 9.19 \\
\hline 5 & 17.0 & 9.06 \\
\hline 6 & 20.0 & 9.02 \\
\hline 7 & 25.0 & 8.89 \\
\hline 8 & 30.0 & 8.60 \\
\hline 9 & 35.0 & 8.63 \\
\hline 10 & 40.0 & 8.27 \\
\hline
\end{tabular}

Notes: *The original data, reported in terms of kilo Pascal (kpa), have been converted into psi using $0.145 \mathrm{psi} / \mathrm{kpa}$.

Sources: Guerrieri, DA., Caffrey, J. , \& Rao, V., Investigation into the Vehicle Exhaust Emissions of High Percentage Ethanol Blend. SAE paper \#950777, 1995, Table 1.

\section{The Function of Base Fuel in Counteracting Higher Volatility}

The CARB Twelve-Vehicle Study determined that ozone forming potential is increased in an ethanol-blend reformulated gasoline - thus, the 1 psi exemption for $10 \%$ ethanol, provided for in Health and Safety Code Section 43830(g), is not operative. However, CARB raised the oxygen cap to $3.5 \mathrm{wt}$ \% (allowing an 8psi RVP maximum), which allows blending of ethanol to $10 \%$ volume. Combined, the impacts of these two decisions by CARB are that if blended with 10 vol. \% ethanol, gasoline must meet the 7 psi RVP requirement.

In CEC's report, Supply and Cost of Alternatives to MTBE in Gasoline. Technical Appendices: Ethanol Blending Properties for Task 3 Modeling Work, six 10\% ethanol blends were considered. Two of them have RVP for base blend of gasoline at the RVP of 5.4 and 5.6 psi respectively. The finished ethanol blends have RVP of 6.8 and 6.9 psi respectively. (See Exhibit 1 of the above cited report; original data from the CRC.)

Issue: Does the RVP level of the base gasoline affect the increase in RVP of gasoline blended with ethanol and other oxygenates?

Analysts have looked at utilizing a base gasoline with a decreased RVP to allow for the increase in RVP that 10 vol. \% ethanol blends add. One such study (Pace Consultant, Inc. 1998) focused on determining the technical requirements for producing a reformulated gasoline (RFG) blendstock suitable for ethanol blending in summer grade Phase II RFG. Costs were also assessed in comparison to MTBE RFG II blends. 
The Pace study examined a set of refinery case studies with ethanol based RFG blends, using the federal RFG Phase II's Complex Model. MTBE-based RFG was referenced as the base comparison to three ethanol-based RFG scenarios. The analysis showed that "a typical refinery blendstock for oxygen blending (RBOB) RVP of 5.6 psi would be required to blend ethanol to RFG to achieve Phase II emissions reduction requirements. The corresponding RBOB RVP for MTBE-based RFG is 6.9 psi. Phase II RVP regulation requires 7.0 psi for compliance. Table 3-2 illustrates data extracted from each of these case studies.

Table 3-2. Blending RVP Case Studies

\begin{tabular}{|l|l|l|l|l|c|}
\hline Case & \multicolumn{1}{|c|}{ Description } & \multicolumn{1}{|c|}{$\begin{array}{c}\text { Pool VP } \\
\text { (psi) }\end{array}$} & $\begin{array}{l}\text { *RBOB RVP } \\
\text { (psi) } \\
\text { for use with } \\
\text { Ethanol }\end{array}$ & $\begin{array}{c}\text { Cost Using } \\
\text { Ethanol vs. Base } \\
\text { Case 1 in \$/Gal }\end{array}$ \\
\hline $\mathbf{1}$ & $\begin{array}{l}\text { Base Case } \\
\text { MTBE-based RFG }\end{array}$ & 7.5 & - & 7.4 & -- \\
\hline $\mathbf{2}$ & $\begin{array}{l}\text { Reduce FCCU and } \\
\text { Isomerization Unit } \\
\text { Throughput }\end{array}$ & 7.0 & 5.6 & 6.9 & $\$ 2.40$ \\
\hline $\mathbf{3}$ & $\begin{array}{l}\text { Sell Light Naphtha as } \\
\text { Petrochemical Feedstocks }\end{array}$ & 7.0 & 5.6 & 6.9 & $\$ 0.79$ \\
\hline $\mathbf{4}$ & $\begin{array}{l}\text { Fractionate C5s from } \\
\text { FCCU Gasoline } \\
\text { Adjust Alkylation }\end{array}$ & 7.0 & 5.6 & 6.9 & $\$ 0.07$ \\
\hline
\end{tabular}

Source: Pace Consultants Inc. ${ }^{19} \quad$ * Refinery Blendstock for Oxygen Blending

PACE found that it is "technically feasible for a relatively complex refinery having a high degree of flexibility for varying the blends and making adjustments in unit operations and in the manufacture of other products." The study results indicate the primary constraint associated with using ethanol blends is the surplus of light (high vapor pressure) naphtha, primarily pentanes and pentylenes (C5s). However, Case 4 assumed that $\mathrm{C} 5$ olefins could be selectively alkylated. In addition, although not specifically discussed in the PACE study, fractionated pentanes and pentylenes can be stored in pressurized systems for later use in low-RVP season (Graboski and Reynolds, 2001). ${ }^{20}$ The costs can also be mitigated by selling the naphtha as shown in Case 3, and as is done at Clark Refinery in California (Yancey 1999). Clark has been successful in finding a market niche in Mexico for the light-end naphtha, but it is unknown how much further that market can be extended.

In the interim years between 1998 and the date of publication, the regulatory context has changed somewhat, particularly in California, where Phase 3 regulations became

\footnotetext{
${ }^{19}$ Pace Consultants Inc., November 1998, Analysis and Refinery Implications of Ethanol-Based RFG Blends under the Complex Model Phase II, Table 1: Refinery Model Case Summary.

${ }^{20}$ Dan Foley of Jacobs Consultancy (formerly Pace Consultants Inc.) stated that C5 storage is a common refinery practice, (telephone conversation, March 4, 2002).
} 
effective in September 2000. As part of Phase 3, a revised predictive model was developed to provide guidance to refiners for gasoline certification. The model includes provision for a total hydrocarbon (THC) emission credit when gasoline formulas include RVP measurements below 6.9 psi. In exchange for lowering RVP and sulfur, Phase 3 provides for increasing T50, T90, and aromatics, which can, in certain circumstances, be valuable in the octane replacement process (Graboski and Reynolds, 2001).

With respect to the implications for using higher ethanol blends, blending qualities relating to volatility have not been fully explored and could be beneficial, particularly under Phase 3 requirements that provide advantages for low RVP and sulfur formulations. In addition, utilizing more ethanol would extend the gasoline supply, which could be particularly critical in California as the December 2002 deadline for removing MTBE from California gasoline draws closer. ${ }^{21}$

Phase 3 also provides for a THC credit when using formulations up to $3.5 \mathrm{wt}$ \% oxygen, which result in carbon monoxide reduction. Ten percent ethanol blends, containing 3.5 wt. \% oxygen, result in CO reductions (Myron 1985; CARB 1997; National Research Council 1999), and are permissible under California rules. However, higher percentages of oxygen can affect other emission levels, including $\mathrm{NO}_{\mathrm{x}}$. Under the predictive model, $\mathrm{NO}_{\mathrm{x}}$ is expected to increase in blends with more than 5.7 vol. \% ethanol ( $2 \mathrm{wt} . \%$ oxygen) thus encouraging California ethanol blending at $5.7 \mathrm{vol} . \% .{ }^{22}$ Following this line of reasoning, the predictive model will effectively discourage the use higher ethanol blends in California, (assuming a waiver permitting their use is obtained - see discussion in the Regulatory and Policy Section), since they contain between 17 and 24 vol. \% ethanol, and could thus produce high $\mathrm{NO}_{\mathrm{x}}$ emissions. ${ }^{23}$

However, Phase 3 requirements in California could prompt the production of base fuels that are significantly lower in sulfur, which will in turn, lower the $\mathrm{NO}_{\mathrm{x}}$ emissions from the base fuel portion of a higher ethanol blend. ${ }^{24}$ Such a $\mathrm{NO}_{\mathrm{x}}$ reduction would not have been characteristic in California Phase 1 or 2, or Federal Phase II gasoline blendstocks. Even though Guerrieri ${ }^{25}$ data show an increase in $\mathrm{NO}_{\mathrm{x}}$ from tests of nine gasoline/ethanol blends ranging from 10 to 40 vol. \% ethanol, it is not known how Phase 3 base fuels could influence $\mathrm{NO}_{\mathrm{x}}$ emission levels without further analysis.

Finally, ethanol emission controls become better understood as more flex-fueled vehicles are in use - and emission profiles of higher ethanol blends could vary if used in an E85

\footnotetext{
${ }^{21}$ Telephone conversation, Mike McCormack, CEC, March 8, 2002.

${ }^{22}$ Ibid

${ }^{23}$ Peer review comments, Bob Reynolds, Downstream Alternatives, October 31, 2001

${ }^{24}$ Automotive Alliance data showing NOx reductions in lower sulfur fuels are seen in http://www.arb.ca.gov/cbg/meeting/2001/AlliancePrestn.pdf., and the trend of NOx emission reductions in low sulfur Phase 3 gasoline is discussed in Refining Industry Preparation for California CBG, September 2001, pg. 6.

${ }^{25}$ Guerrieri, DA., Caffrey, J. , \& Rao, V., Investigation into the Vehicle Exhaust Emissions of High Percentage Ethanol Blend. SAE paper \#950777, 1995.
} 
fuel control system, or in one specifically calibrated for E24. ${ }^{26}$ Certainly, additional testing is needed to confirm higher ethanol blend emissions with Phase 3 base fuels, both in conventional and specially calibrated fuel control systems.

\section{Issue: What about using ETBE as oxygenate?}

Used as an oxygenate, ethyl tertiary butyl ether (ETBE) has low volatility; its RVP is 4, compared to current Federal standards of 7.2 psi in warm climate and 8.1 psi in cooler areas. ETBE's octane rating is relatively high: $(\mathrm{R}+\mathrm{M}) / 2=112,{ }^{27}$ compared to a standard value of 87 for standard unleaded gasoline. An 11 vol. \% MTBE blend has a RVP of 8.1 psi, while a 13 vol. \% ETBE blend has a RVP of 7.6 psi. When it is raised to a 17 vol. \%, RVP falls to 7.3 psi. With a low butane blend, RVP can be reduced to 6.8 psi (Schlanger 1994; Potter 1994). It is therefore feasible to reduce the volatility of the reformulated gasoline by using ETBE in place of ethanol. However, like MTBE, ETBE is an ether. One concern is whether ETBE will have the same adverse health effects as MTBE in the long run. Thus, the recommendation from the University of California study with respect to ethanol and any other alternative oxygenate to MTBE is applicable: a comprehensive environmental assessment is necessary before widespread application of ETBE as oxygenate in RFG occurs.

\section{Other Emissions Testing}

Guerrieri, Caffrey, and Rao (1995) conducted a test of six in-use vehicles on a base gasoline and nine gasoline/ethanol blends with increasing ethanol content from $10 \%$ to $40 \%$. Using simple linear regression, they found significant negative relationships between the ethanol content in the fuel and exhaust emissions of total hydrocarbon (THC), organic matter hydrocarbon equivalent emissions (OMHCE), and CO for all six cars, as well as a significant negative relationship between ethanol content and carbon dioxide $\left(\mathrm{CO}_{2}\right)$ for five cars, with the other car showing no relationship. On the other hand, there are significant positive relationships between ethanol content and the exhaust emissions of acetaldehyde and $\mathrm{NO}_{\mathrm{x}}$. For exhaust formaldehyde emissions, the test results were conflicting: four cars with a significant positive relationship and two cars with significant negative relationship (Guerrieri, Caffrey, \& Rao 1995. Table 6).

Similar results were found using average percentage changes in emissions from base level and ethanol content. Emissions of OMHCE, THC, and CO decreased as the ethanol content rises, while emissions of $\mathrm{NO}_{\mathrm{x}}$ and acetaldehyde rose with the percentage content of ethanol in the fuel blend. Emissions of formaldehyde and carbon dioxide were only slightly affected by the ethanol content in the fuel (Guerrieri, Caffrey, \& Rao, 1995. Figure 1 through Figure 7).

Further, with respect to CO, when emissions assessments were conducted in the 1980 s on $10 \%$ ethanol blends, significant CO reductions were observed. Generally, the vehicles of

\footnotetext{
${ }^{26}$ Discussion introduced in peer review comments submitted by Sean Huff, Oak Ridge National Laboratory, December 19, 2001.

${ }^{27} \mathrm{R}$ is for RON, research octane number. $\mathrm{M}$ is for MON, motor octane number.
} 
that time period were characteristically rich on start-up, so enleaning (adding oxygen) the fuel significantly lowered cold-start emissions (Myron 1985). In 1997, CARB data corroborated $\mathrm{CO}$ reduction trends in data that forecast a $60 \%$ reduction in $\mathrm{CO}$ emissions by 2000 if all of California gasoline included 10 vol. \% ethanol. A recent National Research Council (1999) report cites tests showing CO levels decreasing for 10\% ethanol blends. Brazilian data (see further discussion below) also show a CO decrease in both E22 and neat ethanol (Faiz 1996).

The National Research Council indicates in its 1999 study that CO plays a pivotal role in ozone formation. The study states: "CO in exhaust emissions from motor vehicles contributes about $20 \%$ to the overall reactivity of motor-vehicle emissions. Further, as volatile organic compound (VOC) emissions from mobile sources continue to decrease in the future, $\mathrm{CO}$ emissions might become proportionately an even greater contributor to ozone formation." (NRC 1999 p. 5)

In addition to assessing CO's influence, characterizing $\mathrm{HC}$ levels is the primary basis for determining ozone-forming potential (OFP) and specific reactivity (SR). California regulations assign a maximum incremental reactivity (MIR) value to individual compounds emitted in automobile exhaust. The MIR value is determined in a laboratory setting where a small amount of the substance in question is introduced to a simulated urban air quality mixture, and then the net increase in ozone is measured. When the MIR values for all measured exhaust compounds are taken into account, the OFP can be calculated. Specific reactivity is also calculable by combining the respective mass of compound emissions per mile with the OFP, resulting in a measurement of units of milligrams of ozone per milligram of total organic emissions.

To clarify further, these terms were recently defined in a report published by NREL (NREL, Light-Duty Alternative Fuel Vehicles: Federal Test Procedure Emission Results, 1999). First, ozone-forming potential gives an estimate of the amount of ozone formed per mile traveled. Specific reactivity is distinguished from ozone-forming potential by "giving an estimate of the amount of ozone formed per gram of non-methane organic gases (NMOG)." The term NMOG is a precise form of HC measurement, and represents "the sum of non-oxygenated and oxygenated HCs" in a gas chromatograph sample.

Ambient air quality data provide an additional picture pertaining to ozone formation. One of the most important case studies for the use of ethanol-blended reformulated gasoline is the Chicago area. The American Lung Association of Metropolitan Chicago (ALA/MC) identified ethanol-blended reformulated gasoline as the first of the top six strategies in reducing VOC emissions in Metropolitan Chicago between 1990 and 1998. With data submitted by the Illinois Environmental Protection Agency to the U.S. EPA, ALA/MC estimated that the strategy led to a reduction of 112.8 tons/day of VOC-nearly $10 \%$ (American Lung Association 1999).

Unlike the Guerrieri data which shows a negative relationship between total HCs and ethanol volume, the NREL data for E85 fuels indicate that generally the ozone-forming potential is higher but the specific reactivity is significantly lower. NREL described this 
trend in this way: "Although the $\mathrm{HC}$ emissions from the E85 tests were significantly less reactive, the total $\mathrm{HCs}$ from this subset of vehicles were significantly higher when tested on E85 compared to the same vehicles tested on RFG." With respect to $\mathrm{NO}_{\mathrm{x}}$ emissions, the NREL data differs from the Guerrieri data by showing decreased $\mathrm{NO}_{\mathrm{x}}$ levels in the E85 tests.

Air toxics also affect ozone formation. Air toxics are pollutants known to have adverse effects on human health, which are specifically classified as known or probable carcinogens. EPA has established risk factors for air toxic pollutants, which give an indication of the relative risk of each toxic compound. Table 3-3 lists the EPA risk factors.

Table 3-3 EPA Unit Risk Factors for Air Toxic Emissions

\begin{tabular}{|l|l|l|}
\hline Compound & EPA Risk $\left(\boldsymbol{\mu g} / \mathbf{m}^{3}\right)-1$ & EPA factor (normalized) \\
\hline 1,3 -butadiene & $2.8 \times 10^{-} 4$ & 1.000 \\
\hline Benzene & $8.3 \times 10^{-} 6$ & 0.030 \\
\hline Formaldehyde & $1.3 \times 10^{-} 5$ & 0.046 \\
\hline Acetaldehyde & $2.2 \times 10^{-} 6$ & 0.008 \\
\hline
\end{tabular}

Source: National Renewable Energy Laboratory, 1999, pg. 3.

Using these factors, air toxics can be reported in "potency weighted toxics" which can be a useful comparison to mass emissions. The weighting factor for each compound is determined by dividing its individual risk factor by the risk factor of the most toxic compound (i.e., 1,3-butadiene). To calculate the potency weighted toxic value, the resulting number is multiplied by the respective compound mass emissions.

The air toxic trends seen in the NREL E85 data are as follows:

- Average aldehyde emissions, including formaldehyde (HCHO) and acetaldehyde $\left(\mathrm{CH}_{3} \mathrm{CHO}\right)$ tended to be higher from the E85 tests compared to the RFG tests

- Average 1,3-butadiene, benzene, and the total potency weighted toxic emissions tended to be much lower in the E85 tests compared to the RFG tests.

Even though the aldehydes were significantly higher from E85, (largely due to acetaldehyde being a by-product of ethanol combustion), both formaldehyde and acetaldehyde are only a fraction of the potency of 1,3-butadiene and benzene. Because of this, the "total potency" is significantly lower for the E85 than for the RFG, 44.2\% less in one test series.

Finally, another key issue pertaining to ozone-formation is fuel volatility. As was mentioned previously, data indicate that the volatility of higher ethanol blends decreases as the volume of ethanol increases. The point at which volatility decreases is highly dependent on the qualities of the base fuel, but generally, a downward trend is observed at 17 vol. $\%$. 


\section{Brazilian Emissions Data}

Limited emissions data from Brazil's ethanol fuel program also show relationships between ethanol content in blended gasoline and emissions. The data on relative emissions for $\mathrm{CO}, \mathrm{HC}, \mathrm{NO}_{\mathrm{x}}$, and aldehydes for the different ethanol blends compared to $100 \%$ gasoline (G100) from the Brazilian ethanol fuel program are shown in Table 3-4. Selected blends such as hydrous ethanol (E100), 95\% ethanol (E95/G5), 12\% ethanol (E12/G88), 60\% ethanol, 33\% methanol, and 7\% gasoline (E60/M33/G7) have lower emissions of $\mathrm{CO}, \mathrm{HC}$, and $\mathrm{NO}_{\mathrm{x}}$, than the $100 \%$ gasoline blend. The only exception is for the $24 \%$ ethanol blend for $\mathrm{NO}_{\mathrm{x}}$ emissions. In addition, for $\mathrm{CO}$ and $\mathrm{HC}$, emissions levels are lower for gasoline blended with higher concentrations of ethanol. In the case of aldehydes emissions, ethanol-blended fuels have higher levels of emissions than the $100 \%$ gasoline blend. Further, aldehydes emissions level increased with ethanol content.

\section{Table 3-4 Relative Emissions Brazil's Ethanol Fuel Program}

\begin{tabular}{lcccr} 
& \multicolumn{5}{c}{ Relative Emissions with $\mathrm{G} 100=100$} \\
& $\mathrm{CO}$ & $\mathrm{HC}$ & $\mathrm{NO}_{\underline{x}}$ & Aldehydes \\
& 29 & 71 & 86 & 1,000 \\
Hydrous ethanol (E100) & 36 & 79 & 86 & n.a. \\
$95 \%$ ethanol (E95/G5) & 50 & 87 & 120 & 360 \\
$24 \%$ ethanol (E22/G78) & 81 & 96 & 92 & n.a. \\
$12 \%$ ethanol (E12/G88) & & & & 540 \\
$60 \%$ ethanol,33\% methanol and & 28 & 64 & 97 & \\
$7 \%$ gasoline (E60/M33/G7) & & & & \\
Notes: n.a. Not available. & & & &
\end{tabular}

Sources: Derived from Faiz, A.; Weaver, C. S.; and Walsh, M.P., Air Pollution from Motor Vehicles, Standards and Technologies for Controlling Emission, The World Bank, 1996. Box 5.5, p. 207. Original table presented the data with the relative emission for hydrous ethanol (E100) as 100. The current table is computed by setting the values for $100 \%$ gasoline blend (G100) to 100 .

Regardless of ethanol blending level, adequate infrastructure for storing, transporting, and distributing ethanol to the end-user is important for the viability of ethanol as a transportation fuel. This issue is addressed in the next section. 


\section{Infrastructure Issues}

Adequate transportation and distribution of ethanol is key to deploying higher ethanol (E17-E24) blends. The existing infrastructure will need to be modified, although some of the modifications needed in California, for example, have been, or are currently being made to accommodate increased ethanol use since the MTBE phase-out began. The greatest challenges are the corrosive nature of ethanol and its propensity to absorb water.

With respect to the California market, because the majority of ethanol's current production capacity is located in PADD II (Midwest), transportation costs to the California market are a consideration. Two of the largest Midwestern ethanol producers indicate that ethanol product could be delivered to the California market, based on increased volume to offset increased transportation costs per unit. Archer Daniels Midland, the largest U.S. ethanol producer, would likely use their own dedicated rail car system to minimize transportation costs. Williams Ethanol Services, the second largest ethanol producer in the U.S., indicate that ethanol could be transported by barge to the Gulf Coast and loaded on ocean-going barges designated for the California market.

\section{Distribution Infrastructure}

Ethanol can be delivered to all of California through rail or tanker truck transport from the Midwest or by ship from the Gulf Coast. Due to ethanol's special handling and distribution requirements, distribution infrastructure modifications could include segregated storage tanks, railroad spurs, and additional tanker truck loading equipment.

In the past, refiners have hesitated to make initial capital investments necessary for producing ethanol-based RFG blends, mainly due to ethanol's economic dependence on the federal excise tax (FET) subsidization. For refiners to ensure acceptable returns on ethanol-based capital investments, returns must occur within the first four years of production, which significantly increases cost per barrel $(\$ 2.50-\$ 3.00$ on a $\$ 15$ million capital investment) (Pace Consultants Inc., November 1998).

The CEC's 1998 analysis estimates terminal modification costs of approximately $\$ 60$ million with a two-year completion period. Some of these modifications have already been instituted (since 1998) to support increased 5.7 vol. \% blending. Table 5-1 provides an itemized breakdown of the total $\$ 60$ million modification costs. 
Table 4-1 Infrastructure Modifications

\begin{tabular}{|l|r|l|}
\hline \multicolumn{1}{|c|}{ Terminal Modifications } & \multicolumn{1}{|c|}{$\begin{array}{c}\text { Cost } \\
\text { (millions of } \\
\text { dollars) }\end{array}$} & $\begin{array}{c}\text { Completion } \\
\text { Period }\end{array}$ \\
\hline $\begin{array}{l}\text { Terminal upgrades to receive rail } \\
\text { shipments, including existing rail facilities } \\
\text { and new rail facility construction }\end{array}$ & $\$ 10$ & up to two years \\
\hline $\begin{array}{l}\text { Terminal upgrades to receive tanker truck } \\
\text { shipments, including existing facilities and } \\
\text { new truck unloading facilities }\end{array}$ & $\$ 9$ & up to two years \\
\hline $\begin{array}{l}\text { Storage tanks upgrades, including existing } \\
\text { tanks and new storage tank construction }\end{array}$ & $\$ 12$ & up to two years \\
\hline $\begin{array}{l}\text { Installation of blending equipment, requiring } \\
\text { modifications to } 150 \text { truck loading lanes }\end{array}$ & $\$ 25$ & up to two years \\
\hline
\end{tabular}

Source: California Energy Commission, Staff Report, 1998.

There is an ethanol supply and distribution network already established in California. The main distribution center has been located initially at the Shore Terminals in Crockett, CA. In addition, California's Tosco Refining has equipped their Sacramento, Martinez, and Colton terminals with ethanol blending infrastructure.

\section{Ethanol-Blend On-Site Storage and Blending}

Although ethanol blending occurs most often at the terminal, another option is blending on-site. Blending on-site relieves the requirement for dedicated underground storage for each blend offered. Previously, for example, an E10 blend required its own storage tank at the retail site. If the retailer also offered E85, an additional storage tank was required, along with separate storage for each octane option offered in gasoline, i.e., 87, 89, or 92. Multiple underground tanks are burdensome and are becoming more expensive for the retailer as underground storage regulations become increasingly stringent.

As a result, on-site multi-product dispensing (MPD) has become a viable option.

Sweden is developing an extensive network to provide flexible fueling options, as shown in Figure 4-2. MPD relies on blending equipment to mix and dispense the desired blend on the retail site, utilizing one underground tank of ethanol and another of gasoline. Thus, a major benefit of MPD is that it reduces tankage requirements, while providing for several ethanol blends of choice, e.g., E10, E20, E40, and E85.

Assuming higher ethanol blends are approved under a new waiver authorizing their use, and assuming automakers would warranty automotive use of higher ethanol blends, such flexibility would render dispensing of higher ethanol blends transparent to the consumer. They would not be required to seek out a special fueling station that carried E20 or E40.

To gain additional knowledge of the effects of higher ethanol blends, one approach would entail demonstrating conventional equipment run on E20 and E40, which would be fueled 
by MPD equipment on-site. Because older vehicles "use up" more of their fuel control system adaptability than do newer vehicles, perhaps Technology 5 vehicles (1996 and newer) could use E40, and Technology 4 vehicles $(1989$ - 1995) could use E20, thereby requiring the Technology 4 fuel control system to make fewer changes. The demonstration could take place at several E85 fueling stations in varying geographic locations, to provide for observation of vehicle operation in different climates. The only infrastructure changes that would be necessary would be the installation of the MPD units.

The results of such a demonstration could be instrumental in further characterizing the effects of higher ethanol blends on conventional vehicle equipment. In addition, the demonstration results could also assist the automakers in assessing the terms under which the use of higher ethanol blends could be warranted. If vehicle operation or emissions were not deleteriously affected, then perhaps E20 could be authorized for use in Technology 4 vehicles; E40 could be authorized for use in Technology 5 vehicles, and E10 could be warranted in all vehicles, as it is currently.

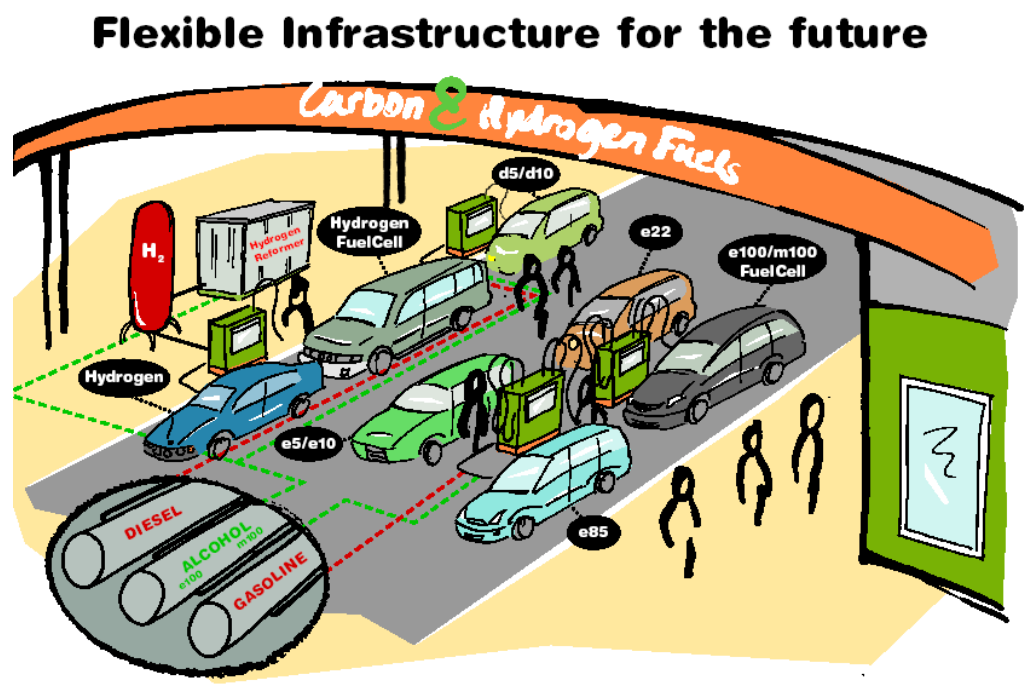

Figure 4-1

Source: BioAlcohol Fuel Foundation, 2002 28

\section{Pipeline Shipment}

Most of the California refineries access pipeline systems connected to terminals throughout the entire state (intrastate). This system enables refiners to transport various refined petroleum products, including gasoline, diesel, and jet fuel, at a lower cost than

\footnotetext{
${ }^{28}$ Provided by Per Carstedt, Chairman, BioAlcohol Fuel Foundation, Sweden; per.carstedt@ecosystem.se
} 
that of rail or tanker truck. Some are equipped to receive product shipments from rail cars and marine vessels.

Historically, studies indicated that petroleum product pipelines were not compatible with anhydrous ethanol's characteristics, because water is completely soluble in ethanol at all concentrations. Once ethanol absorbs enough water from a "wet" pipeline system, it no longer stays blended with gasoline, and forms two liquid phases: a gasoline rich phase and a water/ethanol rich phase. In fact, phase separation due to ethanol's water solubility is the most extensive risk associated with pipeline distribution because the effects are irreversible. Ethanol can only be recovered from the water phase by re-distillation, or in some cases the level might be low enough that only adsorption would be necessary, but this is still costly.

Logistics should be considered as a critical element to pipeline viability. The existing U.S. pipeline infrastructure was developed on a basis similar to that by which PAD Districts (PADD) were established. PADDs were established for the purpose of allocating petroleum resources. Pipeline infrastructure links each point of origin, usually a refinery or natural gas reserve to various markets. Pipelines serve to transport liquids to markets that cannot be accessed by barge or waterway. As a result, pipeline networks have been constructed to ship products in a single direction, primarily south to north and east to west. Ethanol plants are located in grain producing areas where pipelines do not originate. Figure 5-1 illustrates the proximity of PADD II pipelines and ethanol production facilities. 


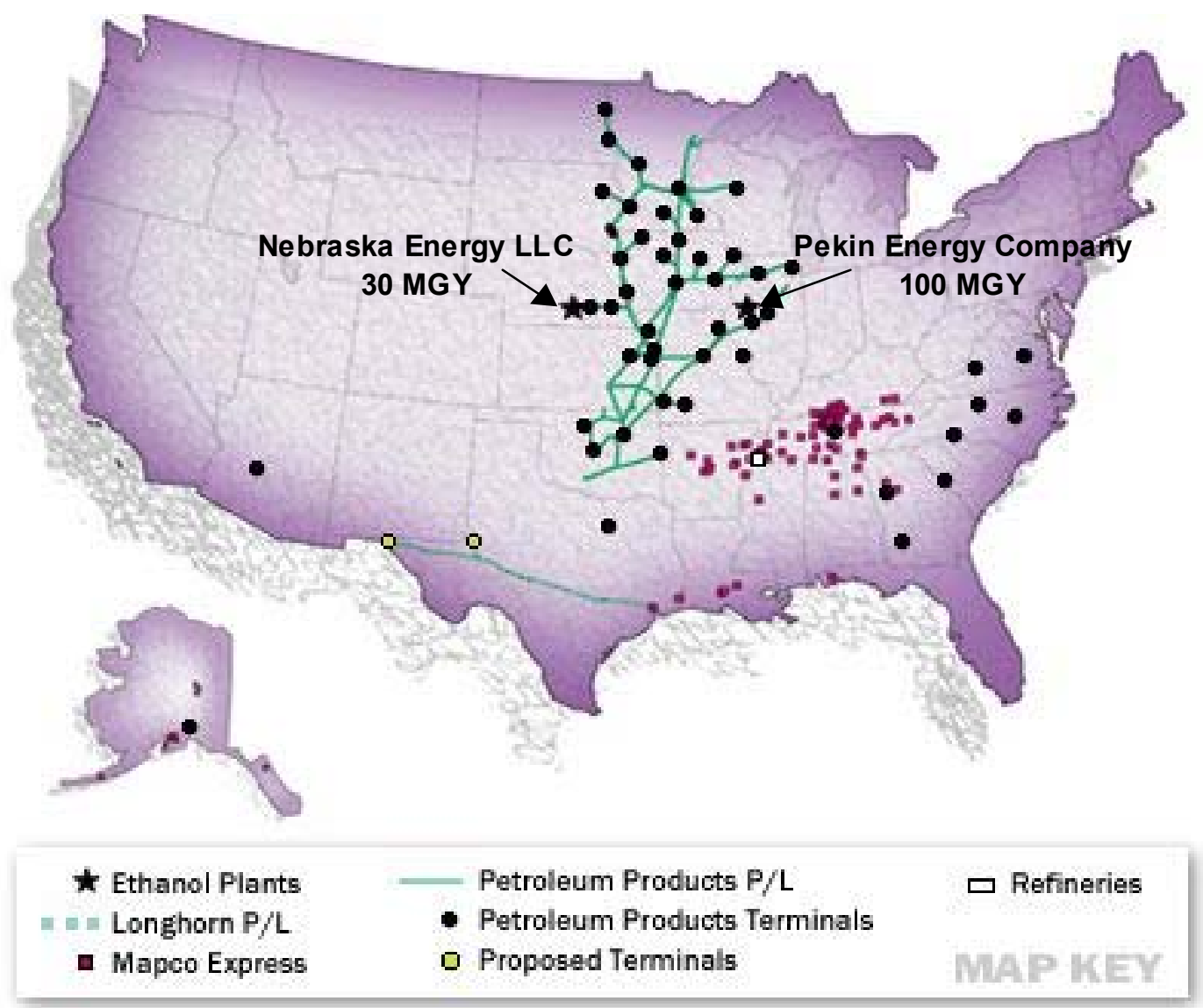

Figure 4-2. Ethanol Plants and Existing Petroleum Pipelines.

Distribution Data:

Storage:

- More than 75 storage terminals located throughout the midwest, southeastern, and southwestern United States

- Features both independent and on-system terminals

- Operates a fleet fuel management service and petroleum trucking operation

Transportation:

- 9,100 mile petroleum products and crude oil pipeline

- Covers an 11-state area in the Midwest

- Moves more than 236,000,000 barrels of refined products per year

Source: http://www.williamsenergy.twc.com

However, intrastate pipeline shipment of ethanol is increasingly important as additional ethanol is used in California. The feasibility of higher ethanol blend pipeline transport is discussed in the next section. 


\section{Pipeline Shipment of Higher Ethanol Blends}

While technically feasible, industry sources have traditionally voiced concerns about shipping ethanol in pipelines, either as a blend or as a neat fuel. Pipeline shipment requires additional capital investments and increased maintenance costs. In particular "drying out" the pipeline is a concern. The additional risk that such investment could become stranded if a viable ethanol market fails to develop further increases risks and uncertainties for pipeline companies. However, if high volumes of ethanol penetrated the California market, refiners might not be as reluctant to dry out intrastate pipeline distribution systems to ship ethanol-blended gasoline from refineries to various distribution terminals.

Pipeline shippers of ethanol in Brazil mitigate phase separation by first shipping hydrous ethanol, followed by a shipment of anhydrous ethanol. ${ }^{29}$ Pipeline test studies have been conducted on neat ethanol as well as gasohol (10\% ethanol blended gasoline), to determine pipeline feasibility for markets within the PADD II region and the Northeast. Brazil, which arguably has the most experience shipping ethanol, never ships any blended fuel, only neat ethanol. Although interstate pipeline shipment in the United States could be geographically problematic, the following data could be more relevant to intrastate pipeline transport in large market areas such as California, the Midwest, or the Northeast.

The pipeline test designs, key results, and relevant discussions follow:

- Amoco Oil Company tested three separate gasohol batch shipments on April 26, 1980, from Kansas City, Missouri to Des Moines, Iowa. The tests confirmed that gasohol (E10) is not only very sensitive to water, it has strong solvent effect, and will remove rust, gum, and varnish much more readily than will conventional gasoline. In addition, the tests revealed that water tolerance of ethanol blends is affected primarily by temperature, ethanol content, and by the aromatic content of the gasoline. Specifically, 5-vol. \% ethanol phase separated in the presence of $0.2 \%$ water, while 10 vol. $\%$ ethanol's separation point was nearly $0.4 \%$ water. The tests also found that the colder the temperature, the more likely the ethanol blends were to separate. The tests showed that pipelining of E10 gasohol blends is considered feasible, but the economics associated with small volumes of gasohol do not justify the investment required to permanently modify the blending and shipping systems (Amoco Pipeline Co., 1981).

The results of the pipeline study have implications for pipelining higher ethanol blends. First, the study indicates that a $10 \%$ blend can tolerate almost twice as much water as a $5 \%$ ethanol blend (i.e., $0.4 \%$ water vs. $0.2 \%$ water) before it separates. Second, the test highlights the importance of temperature to phase separation. Indeed, these results indicate that more work is needed to confirm whether higher ethanol blends would be more stable in warmer regions, even if shipped in pipelines that have not been fully dried out.

${ }^{29}$ Personal communication, Lou Gibbs, Chevron, June 6, 2000. 
Other pipeline tests have been conducted to examine the effects of anhydrous ethanol shipment on commercial pipelines and the effects of E10 shipment in three consecutive shipments of 5000 barrels each. Following, the respective results are discussed.

- In 1981, Archer Daniels Midland Company and Williams Pipeline Company jointly conducted a test to determine whether fuel grade anhydrous ethanol could be transported in neat form by commercial pipeline. The pipeline segment from Kansas City, Missouri to Des Moines, Iowa was selected as a "worse case" system due to water and sludge, but was partially prepared for the shipment by "pigging" an estimated 130 barrels of water and sludge from the line prior to the actual ethanol pump. The study indicated that, although the ethanol picked up color and gum from residue in the pipeline, neat ethanol transportation by commercial pipeline is possible. (Archer Daniels Midland/Williams Pipeline Company, 1981).

- Discussions with Williams Pipeline revealed that neat ethanol pipeline shipments to the Northeast would be possible if the RFG market supported high volumes of ethanol batch shipments (approximately 50,000-barrel lots). If the northeastern area of PADD I chooses ethanol RFG blends, neat ethanol could be batch shipped between regular unleaded and premium unleaded gasoline batch shipments through existing pipelines.

- Archer Daniels Midland, in conjunction with Buckeye Pipeline and Northeast Petroleum Company also performed a pipeline test shipping gasohol (E10) up Buckeye's Jet Line from New Haven, Connecticut to the Armory terminal in Springfield, Massachusetts. The test, performed on September 7, 16, and 22, 1994, consisted of three separate trial shipments of 5000 barrels each pumped during a normal gasoline cycle. Sampling was conducted at three different locations: New Haven, East Hartford, and Springfield. Samples were tested for visual appearance, oxygen content and ethanol, and particular attention was paid to phase separation and product quality. 
The following results were observed:

- Appearance. Various levels of degraded appearance declined with each test, just as the total number of barrels affected also declined with each test. More barrels experienced appearance degradation as the batch moved further up the pipeline. As expected, the cleansing action of ethanol gradually cleaned the pipeline; and residual water in the pipeline diminished due to repeated passes. Other unpublished studies reached similar conclusions.

- Ethanol Content. Sampling from the third site approximated ethanol content to that of the first sampling site, within approximate sampling time frames.

Chemical inhibitors to reduce the corrosive effects of ethanol may be an option. However, developing such inhibitors would require extensive testing to study the inhibitor's behavior in the pipelines and storage, as well as any adverse effects on end use in engines and turbines. ${ }^{30}$ (Archer Daniels Midland/Buckeye Pipeline, 1994).

In summary, the initial Amoco Oil tests in 1981 indicate that blends with greater amounts of ethanol resist separation longer than those with lower percentages of ethanol. They also indicate that blends were more likely to separate in colder temperatures.

As is done in Brazil, neat ethanol shipment by commercial pipeline is seen to be viable in the Archer Daniels Midland and Williams Pipeline pipeline tests and observations.

E10, or gasohol, was successfully shipped in commercial pipelines in consecutive 5000 barrel lots, with results showing decreased levels of degraded appearance and residual water.

Finally, since intrastate pipeline shipment is particularly important to ethanol distribution in the California market, and since higher ethanol blends could exhibit favorable behavior with respect to phase separation, particularly in warmer climates, pipeline testing on E17E24 could provide valuable information.

${ }^{30}$ Personal communication, James Holland, Kinder Morgan, June 2, 2000. 


\section{Ethanol Market Issues}

\section{Background}

Sparked by the energy and farm crises, the modern-day fuel ethanol industry began with the Energy Tax Act of 1978. While the early ethanol markets resulted from market subsidies, environmental issues soon led to additional regulations supporting the use of ethanol. Beginning with Denver in 1987, programs to require the use of "oxygenates" like ethanol and MTBE successfully demonstrated reductions in wintertime CO emissions. Later, RFG, another key market for oxygenates, was introduced to combat ozone.

MTBE has traditionally dominated the RFG market because of its desirable handling characteristics, (e.g., fungibility and pipeline compatibility), and low volatility in gasoline blends. However in a 1999 Executive Order ${ }^{31}$ California Governor Gray Davis cited that "on balance, there is significant risk to the environment from using MTBE in gasoline in California." As a result, ethanol is being seriously examined as a replacement for MTBE. Although MTBE will be in use in California through the fourth quarter of 2002, ${ }^{32}$ California refiners are also using approximately 100-150 million gallons a year of ethanol before the ban as a supplemental oxygenate to MTBE. ${ }^{33}$ Ethanol is the only other oxygenate component currently acceptable in California as an MTBE substitute. ${ }^{34}$ Other RFG areas are also considering the use of ethanol, including the high-demand northeastern sector.

\section{U.S. Production ${ }^{35}$}

Whether or not there is adequate capacity to meet the increased ethanol demand is a key question. The California Energy Commission just completed a survey (CEC, 2001) of 84 ethanol companies in the United States in an attempt to quantify the following: (1) number of new plants planned; (2) number of new plants under construction; (3) existing plant expansions; and (4) existing plants. The time period covered was $2001-2005$.

The survey showed that a major expansion of the U.S. ethanol industry is underway. According to the report, current capacity is approximately 2200 million gallons per year (MGY). If all of the planned expansions take place by 2005, the total capacity is expected to double to $4400 \mathrm{MGY}$. However, researchers assume that approximately $400 \mathrm{MGY}$ will supply the industrial/ beverage markets. ${ }^{36}$ For the purposes of this assessment, a total capacity of 4000 MGY by 2005 is assumed for use in fuel markets.

\footnotetext{
${ }^{31}$ Executive Order D-5-99, March 25, 1999.

${ }^{32}$ Schremp, Gordon, California Energy Commission, LLNL Workshop, Oakland, CA, April 10 - 11, 2001, California Issues - Expanded Use of Ethanol and Alkylates.

${ }^{33}$ Telephone Conversation with Tom McDonald, California Energy Commission, July 19, 2001.

${ }^{34}$ California Environmental Protection Agency, Workshop Regarding Regulatory Fuels Activities, p. 9, August 29, 2001.

${ }^{35}$ The data in this section are largely based on a recent California Energy Commission survey conducted to determine ethanol capacity through 2005, and on technical presentations given by CEC staff.

${ }^{36}$ Telephone conversation with Mike McCormack of the California Energy Commission, October 1, 2001.
} 
To clarify ethanol capacity growth further, for 2002 production capacity is expected to grow to about 3000 MGY by year's end; 4000 MGY at the end of 2003; and 4200 MGY by 2004. As a point of comparison, the report states that the record for US ethanol production took place in 2000, at $1630 \mathrm{MGY}$. A production of $2000 \mathrm{MGY}$ is expected for 2001.

According to the survey, Illinois, Nebraska, Iowa, and Minnesota are currently, and will remain, the top four ethanol-producing states. In terms of planned ethanol projects, South Dakota ranked the highest with 9, followed by Iowa at 8 , and Nebraska and Wisconsin at 3. New plants are currently under construction in Iowa, South Dakota, Nebraska, Illinois, Wisconsin, and Kansas. Montana, Washington, Oregon, and New York are initiating ethanol-producing projects. California has two small ethanol producing plants, and is the site of plans for biomass-ethanol plants for the 2004-2005 time period, pending attainment of technical, economic, and financing goals. (Schremp, 2001)

\section{California Demand}

In 2003, estimates of California ethanol demand for MTBE -replacement range from 660 to $950 \mathrm{MGY}$. The low figure represents the demand if $5.7 \%$ ethanol were blended in $70 \%$ of California gasoline, corresponding with federal RFG requirements (See Figure 5-1) The high figure represents the demand if "spillover" and fungibility issues result in California gasoline containing 5.7\% ethanol across the board. 


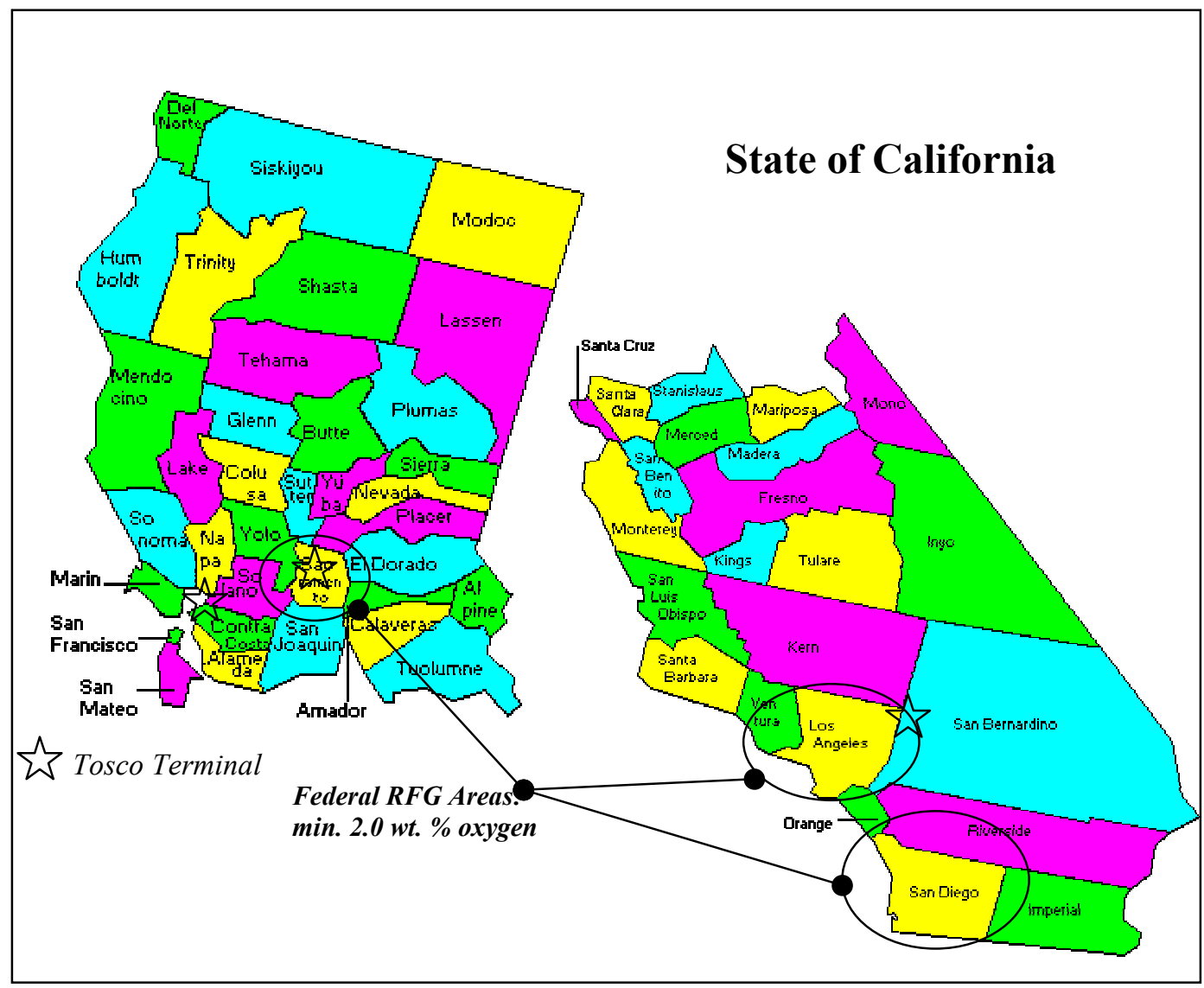

Figure 5-1. Federal RFG Areas in California.

The three Federal RFG areas account for approximately $70 \%$ of all gasoline sold in California. CARB estimates that approximately 14 billion gallons per year of California gasoline contains close to the federal minimum oxygen standard (CARB 1997).

Other factors that will influence the actual ethanol demand increase in California include: (1) the resolution of continuing state appeals for a waiver of federal oxygenated gasoline requirements; (2) progress obtained towards air quality attainment goals; (3) the final MTBE phaseout schedule, as determined by California; and (4) the economics of blending ethanol after the appropriate infrastructure is put in place, and the gasoline formulation practices, as adopted by California gasoline refiners and marketers. (CEC, 2001)

In a presentation in a workshop at Lawrence Livermore National Laboratory (April, 2001), Gordon Schremp of the California Energy Commission estimated that if California converted all of its gasoline supply to $5.7 \%$ ethanol, half of all U.S. production of ethanol would be required. ${ }^{37}$ That estimate assumes that a waiver will not be obtained exempting California from the federal oxygenated gasoline requirements. If only $80 \%$ of California

\footnotetext{
${ }^{37}$ Prior to the completion of the 2001 survey, the $2000-2001$ production figure of 1.8 BGY of ethanol was used as a basis.
} 
gasoline is converted, California demand would be slightly less than half of U.S. production. If a waiver from federal oxygenated requirements is obtained, then the demand, according to Schremp, would be slightly more than $80 \%$.

\section{Other Demand}

Demand for ethanol could jump even more dramatically if other states choose to phaseout MTBE. Some estimates assume that the northeastern demand could equal that of California (Schremp 2001). Combined California and Northeastern demand could range from 1.4 billion gallons per year (BGY) to 2.0 BGY. The high demand scenario for California and the Northeast at 2.0 BGY would equal the expected 2001 production of ethanol at 2.0 billion gallons.

Currently, New York and Connecticut have instituted MTBE bans for 2004 and 2003, respectively, with associated demands of $200 \mathrm{MGY}$ in 2004 for New York, and $80 \mathrm{MGY}$ in 2003 for Connecticut. Because New York's larger demand does not begin until 2004, and because the demand is not yet established for the rest of the Northeast, the northeastern demand could phase-in over time, coinciding with the increased capacity projected for 2005 .

Other ethanol fuel market demand also exists. The MTBE-replacement demand from California and the Northeast is not likely to supplant the long-standing gasohol markets of the Midwest (10 vol.\% ethanol). Ethanol has also played a key role for octaneenhancement in non-RFG, in wintertime oxygenated fuels, and E85 is available in some areas. Estimates for demand outside of California range from 2.3 to 3.1 BGY by 2004 (Schremp, 2001).

\section{Implications for Higher Ethanol Blends}

Based on the estimates given above for both California and other demand, total U.S demand could range from 2.96 $\mathrm{BGY}$ to $4.02 \mathrm{BGY}$. As mentioned previously, if the expected capacity increase takes place as planned, production for fuel markets by 2005 would approximate 4.0 BGY. In the high-demand case, supply would be about even with demand; in the low-demand case, about 1 BGY excess supply would exist.

In view of the uncertainties of the expansion of ethanol capacity and of the MTBEreplacement market, it is premature to project available supply for other uses, including higher ethanol blends. However, as the remaining technical questions are addressed further with respect to using higher ethanol blends in conventional vehicles, and if a new EPA waiver can be obtained (see discussion in next section), higher ethanol blends could represent an additional fuel market, particularly in ozone-attainment areas where volatility is not so critical and where E10 is currently used in $\mathrm{CO}$ non-attainment areas and in gasohol markets, primarily in the Midwest. In the longer term, as additional higher ethanol blend volatility characterization is conducted, and low volatility base fuel supply is established, higher ethanol blends could have applicability in other gasoline markets as well. 
The use of higher ethanol blends could also be seen as a way to absorb excess ethanol if oversupply materializes in the fuel ethanol market. Discussions at the CEC have articulated that FFVs offer the same opportunity. ${ }^{38}$ In addition, research is underway on specially formulated fuels such as the P-Series fuel. Developed by Pure Energy Corporation, the P-Series fuel, (and a related fuel under development called the D-Series fuel), rely heavily on ethanol in proportions ranging from 15 to $30 \mathrm{vol} . \%$, the use of rejected gasoline blends stocks such as pentanes (that would otherwise have to be discarded), and co-solvents that help prevent phase separation. ${ }^{39}$

${ }^{38}$ Telephone Conversation, Mike McCormack, CEC, October 1, 2001

${ }^{39}$ Telephone Conversation, Scott Dunlop from Pure Energy Corporation, October 17, 2001 


\section{Regulatory and Policy Issues}

Both Federal and California fuel requirements have been discussed at length in other sections of this report, primarily with reference to critical oxygen content and volatility parameters. California volatility specifications for summertime RFG and Phase $3 \mathrm{NO}_{\mathrm{x}}$ requirements are particularly pivotal with respect to the potential use of higher ethanol blends. However, as was mentioned earlier, higher ethanol blends will yield a volatility advantage since data indicate that RVP decreases as ethanol content increases and Phase 3 encourages low sulfur base fuels, which will in turn lower the $\mathrm{NO}_{\mathrm{x}}$ levels in the base fuel portion of a higher ethanol blend. Thus, higher ethanol blending characteristics should be further explored within the context of Phase 3 parameters.

This section will review the principal policy driver affecting the use of higher ethanol blends - the EPA "substantially similar" interpretive ruling. In addition, the impact of higher ethanol blends on achieving Energy Policy Act "replacement fuel requirements," and a discussion of the Federal Excise Tax and Blenders Tax Credit in relation to the use of higher ethanol blends will be reviewed. For a complete discussion of other Federal and California regulatory parameters, see Appendix C.

\section{Substantially Similar Fuels}

Under Section 211 (f) (1) (A) of the Clean Air Act Amendments of 1990 (CAAA), fuel and fuel additives marketed in the United States for use in light-duty vehicles must be "substantially similar" to the fuels used by EPA for federal emissions test procedures. This provision applies to any aliphatic ether and/or aliphatic alcohol (excluding methanol), and any combination thereof. Any fuel or fuel additive with more than $2.7 \mathrm{wt}$. $\%$ oxygen is not considered to "substantially similar" unless a waiver is obtained from EPA.

Under Section 211 (f) (4) of the Act, EPA has the authority to grant a waiver if the applicant can demonstrate that the fuel in question will not cause emissions (exhaust and evaporative) to exceed the vehicle emission standards at which the vehicle was certified. In addition, the fuel cannot negatively affect the performance of the vehicle's emission control systems, negatively affect materials compatibility (elastomers or metals), or driveability (e.g., fuel economy or cold or hot start problems.)

There are two types of waivers that can be granted depending on the type of additive being considered. An "instantaneous" waiver applies to an additive that has an immediate affect and that remains constant over time. The second type of waiver is a "durability waiver," referring to an additive that could have a cumulative effect (e.g., the additive MMT includes manganese, which can build up in the engine over time.) 


\section{Regulatory Approval for Higher Ethanol Blends}

In ethanol's case, in 1978 an instantaneous waiver was obtained to permit blends with 3.5 weight percent oxygen, or 10 volume percent ethanol. The commercialization of higher ethanol blends will require a new EPA waiver allowing higher ethanol concentrations.

In applying for a waiver, an applicant would notify EPA of their intent to apply for a new waiver and agree upon an approach. One such approach would be to focus on the highest point in the range of interest (i.e., 24\%) since emission trends observed at $24 \%$ could also apply to blends ranging from $17 \%$ to $23 \%$ (Caldwell 1999). To obtain a new waiver, data would be required to show that negative impacts do not occur on emissions (tailpipe and evaporative), fuel system, emission control system, engine materials, and driveability. In an assessment for higher ethanol blends, fuel economy would likely be considered a driveability issue.

Although EPA has not issued a new waiver in many years, a prescribed application process for an instantaneous waiver has been established (Sopata 1999). Basic steps follow:

- A minimum of eight vehicles are tested, first on an unleaded gasoline that meets federal clean fuel standards, then on the blend in question.

- All emission changes are evaluated, including tailpipe/combustion and evaporative. To accommodate evaporative testing requirements, shed testing would be required.

- Materials compatibility issues are tested in both the fuel system and the engine.

In the past, EPA evaluated changes in regulated pollutants only, i.e., $\mathrm{CO}, \mathrm{NO}_{\mathrm{x}}, \mathrm{THC}$, and particulates. Aldehydes were not considered in 1978 during the gasohol waiver data review since they are not specifically mentioned in the statute. Expanded health effectsrelated testing requirements associated with the registration of fuels or fuel additives have since been instituted. (See Appendix C for further details.)

\section{Replacement Fuels Requirements}

Title V of the Energy Policy Act of 1992 (EPAct) mandates establishment of a replacement fuel supply and demand program, focusing on light-duty vehicles. EPAct mandates a replacement fuels program that covers the ethanol component in a blended fuel, or in nearneat fuels (i.e., E85 and E95). The objectives of EPAct are to reduce the vulnerability of the U.S. transportation system to international oil supply interruptions and price shocks, to improve the health of the economy, and to reduce greenhouse gas emissions. The intent is to substitute, to the maximum extent feasible, domestically produced non-petroleum based alternative fuels such as electricity, ethanol, hydrogen, liquefied petroleum gas, methanol, and natural gas for petroleum-based gasoline and diesel fuels. Section 502(b)(2) of EPAct sets the tentative goals of displacing $10 \%$ of transportation fuel by the year 2000 and displacing $30 \%$ by the year 2010 . 
What role can higher-ethanol blends play in helping to achieve the $30 \%$ alternative fuel goal? In 1997, total ethanol used in transportation amounted to 781.8 million gasoline equivalent gallons (GEG) or 0.0911 quadrillion BTUs (Quads). ${ }^{40}$ It accounted for less than $0.4 \%$ of total transportation use of 24.9 quads computed by the Energy Information Administration (EIA) in Annual Energy Outlook 1999 (EIA 1999). ${ }^{41}$ From 1992 through 1998 , ethanol fuel used for transportation purposes grew at an annual rate of approximately 4.6\%. If the same growth rates for ethanol were assumed to apply between 1997 and 2010, it would amount to 0.164 quads. This would account for about $0.5 \%$ of total projected transportation energy use in 2010 in the base case, $0.52 \%$ in the low economic growth case, and $0.48 \%$ in the high economic growth case. ${ }^{42}$ If the ethanol content in blended gasoline were assumed to be $20 \%$ instead of $10 \%$, starting in 1997 , and the same $4.6 \%$ annual growth rate were applied from 1997 to 2010 for ethanol use, then total transportation use of ethanol would be 0.326 quads. This would account for about $0.99 \%$ of total transportation energy use in the base case; $1.04 \%$ in the low economic growth case, and 0.96 in the high economic growth case.

The corresponding contribution to attaining the $30 \%$ alternative fuel goal in 2010 would be as follows:

$\begin{array}{lcccc} & \underline{\text { Base Case }} & \begin{array}{c}\text { High Econ. } \\ \text { Growth Case }\end{array} & \begin{array}{c}\text { Low Econ. } \\ \text { Growth Case }\end{array} \\ 10 \% \text { ethanol blend } & 1.7 \% & & 1.6 \% & 1.7 \% \\ 20 \% \text { ethanol blend } & 3.3 \% & 3.2 \% & 3.5 \%\end{array}$

In other words, without changes to the current ethanol content of $10 \%$, ethanol would contribute about $1.7 \%$ of the 2010 alternative fuel goal. If the ethanol content were increased from $10 \%$ to $20 \%$, then ethanol's 2010 contribution to the alternative fuel goal would be $3.3 \%$.

Other background information on replacement fuels requirements is included in Appendix C.

\section{Federal Excise Tax and Blenders Tax Credit}

The FET Exemption was recently extended through 2007. The FET is limited by statute to ethanol blends of no more than $10 \mathrm{vol}$. \%, or pro-rated levels of $2.0 \mathrm{wt} . \%(5.7 \mathrm{vol} . \%)$ or 2.7 wt. \% (7.7 vol. \% ). This constraint precludes applying the FET to any blend higher than 10 vol.\%. Thus, the only option open to blenders who are blending at levels higher than 10 vol. \% is the Blender's Tax Credit (BTC). In practice, the BTC has seen limited use since its enactment in 1981, primarily because it is a non-refundable credit that is subject to alternative minimum tax (AMT) limitations. Very few gasoline blenders (and even major gasoline refiners) have sufficient tax liability exempt from AMT

\footnotetext{
${ }^{40}$ One gasoline equivalent gallon (GEG) is equal to 115,000 BTUs. For details for the calculations in this discussion, see Appendix A.

${ }^{41}$ Using the values provided in EIA's Alternatives to Traditional Transportation Fuels 1996, ethanol's share would have been approximately $0.5 \%$.

${ }^{42}$ Projections of total transportation energy use are derived from EIA, 1999, Table B7, p. 151.
} 
coverage that would allow full use of the BTC, even when meaningful volumes of ethanol usage are involved. In contrast, at E10 and below, blenders simply do not pay the FET (currently 5.3 cents per gallon of E10 gasoline) at the point-of-sale.

Thus, the parameters of how the federal excise tax and blender's tax credit are applied discourage blending of higher percentages of ethanol. This situation can only be remedied if Congress modifies the tax code. 


\section{Summary, Conclusions, and Recommendations}

This report has examined issues associated with using higher ethanol blends in the transportation sector. Currently, 5.7 - 10 vol. \% ethanol blends are used in wintertime CO markets, federal and state reformulated gasoline programs, and in conventional gasoline for octane enhancement and gasohol markets. Can higher ethanol blends be used instead to fill these markets and others? What changes would be necessary to vehicle systems, including fuel control systems and fuel system components? What impact would there be on emissions? Would driveability be affected? What would the implications be with respect to transportation infrastructure? And finally, what regulatory changes would be required to accommodate higher ethanol blends?

This report has presented the issues that affect the questions mentioned above. In some cases, there are no clear, definitive answers because further assessment is required. In other cases, the data provide clearer trends. The following summarizes key conclusions, open issues, and recommendations for further action. 


\section{Table 7-1 Key Conclusions, Open Issues, and Recommendations}

\begin{tabular}{|c|c|}
\hline Key Conclusions & $\begin{array}{l}\text { Key Open Issues and } \\
\text { Recommendations }\end{array}$ \\
\hline \multicolumn{2}{|c|}{ Chapter II: Technical Issues } \\
\hline $\begin{array}{l}\text { 1. Higher ethanol blend impact on } \\
\text { conventional fuel systems could vary } \\
\text { according to control system technology and } \\
\text { vehicle age } \\
\text { W3 } \\
\text { infler oxygen parameters could } \\
\text { influence operation } \\
\text { Independent testing on E20 blends } \\
\text { indicate that stoichiometric conditions } \\
\text { were achieved } \\
\text { 2. Higher ethanol blends will operate } \\
\text { effectively on conventional vehicle } \\
\text { catalysts }\end{array}$ & $\begin{array}{l}\text { 1. Recommend testing on the range of } \\
\text { vehicle technology classes to confirm } \\
\text { higher ethanol blend effect. } \\
\text { 2. Vehicle warranty concerns among vehicle } \\
\text { manufacturers are an open issue. } \\
\text { 3. Manufacturer involvement is needed to } \\
\text { assess the issues surrounding the use of } \\
\text { higher ethanol blends. }\end{array}$ \\
\hline \multicolumn{2}{|c|}{ Chapter III: Emissions and Emissions Testing } \\
\hline $\begin{array}{l}\text { 3. Preliminary emissions data indicate that } \\
\text { the volatility of higher ethanol blends is } \\
\text { less than in } 10 \% \text { blends. } \\
\text { 4. To meet RVP requirements, refiners can } \\
\text { produce gasoline with a lower RVP } \\
\text { 5. CO emissions are typically lowered in } \\
\text { ethanol blended fuels. This trend could } \\
\text { also influence the rate of ozone formation } \\
\text { in the atmosphere. } \\
\text { 6. E85 data show different trends for "ozone- } \\
\text { forming potential" and "specific } \\
\text { reactivity" } \\
\text { 7. California Phase } 3 \text { parameters for low } \\
\text { sulfur and RVP fuels could encourage the } \\
\text { production of low sulfur base fuels, which } \\
\text { could in turn influence NOx levels in } \\
\text { higher ethanol blends }\end{array}$ & $\begin{array}{ll}4 . \quad \text { Testing recommended: } \\
\text { To further characterize higher ethanol } \\
\text { blend volatility decreases and } \\
\text { associated base fuel characteristics } \\
\text { To confirm } \mathrm{NO}_{\mathrm{X}, \mathrm{CO} \text {, and air toxic }} \\
\text { emissions } \\
>\text { To quantify emission changes after } \\
\text { specifically calibrating the vehicle's } \\
\text { emission control system for E24 } \\
\text { (Recommended by Huff, 2001) } \\
\text { 5. With respect to ozone formation, } \\
\text { recommend further analysis to determine } \\
\text { net effect of lower CO and higher NOX. } \\
\text { 6. Recommend calculating "ozone-forming } \\
\text { potential" and "specific reactivity" for } \\
\text { higher blends. }\end{array}$ \\
\hline
\end{tabular}

\footnotetext{
${ }^{43}$ Data indicate (Guerrieri 1995) conventional fuel management systems can operate on ethanol blends up to 42 vol. \% ethanol. However, Guerrieri's results indicate that the air/fuel ratio becomes increasingly lean as greater quantities of ethanol are added, with expected changes in emissions, (i.e., higher $\mathrm{NO}_{\mathrm{x}}$ and acetaldehyde; lower OMHCE, THC, and CO. Gardiner (1999) hypothesizes that higher ethanol blends would fall well within the fuel control system "band of adjustment in some vehicles."

${ }^{44}$ Until 1997, Brazilian E22 vehicles were equipped with catalytic converters based on platinum and palladium. However, in recent years, catalyst formulations for gasohol and neat ethanol vehicles have been standardized to be similar to those in the U.S. market. Szwarc assumes E17 - E24 blends would in most instances be compatible with conventional vehicle catalysts, providing the necessary conditions exist, including temperature (Szwarc 1999).
} 


\begin{tabular}{|c|c|}
\hline Key Conclusions & $\begin{array}{l}\text { Key Open Issues and } \\
\text { Recommendations }\end{array}$ \\
\hline \multicolumn{2}{|c|}{ Chapter IV: Infrastructure Issues } \\
\hline $\begin{array}{l}\text { 8. Some infrastructure modifications have } \\
\text { already taken place to support the } 100 \\
\text { MGY of ethanol usage in California } \\
\text { 9. Pipeline studies indicate higher ethanol } \\
\text { blends may be more conducive to pipeline } \\
\text { shipment, particularly in warm } \\
\text { temperatures. } \\
\text { High ethanol volumes in California could } \\
\text { justify the expense of "drying out" } \\
\text { intrastate pipelines. } \\
\text { 10. Separate tankage for ethanol storage is } \\
\text { already established at E85 fueling stations. } \\
\text { Separate handling and storage for E17- } \\
\text { E24 would be avoided by blending at the } \\
\text { pump for E10, E20, or E85. Existing } \\
\text { infrastructure would thus be used to its } \\
\text { greatest benefit. }\end{array}$ & $\begin{array}{l}\text { 7. Recommend further assessment to } \\
\text { determine remaining infrastructure } \\
\text { changes needed to replace MTBE. } \\
\text { 8. Recommend further pipeline testing to } \\
\text { further quantify: } \\
\text { The water tolerance of } 17-24 \text { vol. \% } \\
\text { blends } \\
\text { The effect of a warmer climate on } \\
\text { water tolerance } \\
\text { The impact of greater water tolerance } \\
\text { on the cost of special handling practices } \\
\text { for higher ethanol blends. } \\
\text { 9ulti-blend dispensing pumps are being } \\
\text { used commercially in Sweden. } \\
\text { Recommend conducting U.S trials using } \\
\text { these pumps at E85 stations. }\end{array}$ \\
\hline \multicolumn{2}{|c|}{ Chapter V: Ethanol Market Issues } \\
\hline $\begin{array}{l}\text { 11. Total U.S. demand could range between } \\
2.96 \text { BGY and } 4.02 \text { BGY in the } 2003- \\
2004 \text { time period. Expected capacity for } \\
\text { ethanol fuel markets could reach } 4.0 \text { BGY } \\
\text { by } 2005 \text {. In the high demand case, supply } \\
\text { would be about even with demand; in the } \\
\text { low demand case, about } 1 \text { BGY excess } \\
\text { supply would exist. } \\
\text { 12. It is premature to project available ethanol } \\
\text { supply for other uses, in view of the } \\
\text { uncertainties related to the expansion of } \\
\text { ethanol capacity, and of the MTBE- } \\
\text { replacement market. }\end{array}$ & $\begin{array}{l}\text { 10. Address remaining technical questions and } \\
\text { obtain a new EPA waiver to "set the } \\
\text { stage" for higher ethanol blend use should } \\
\text { excess capacity become available. }\end{array}$ \\
\hline
\end{tabular}




\begin{tabular}{|c|c|}
\hline Key Conclusions & $\begin{array}{l}\text { Key Open Issues and } \\
\text { Recommendations }\end{array}$ \\
\hline \multicolumn{2}{|c|}{ Chapter VI: Regulatory and Policy Issues } \\
\hline $\begin{array}{l}\text { 13. Higher ethanol blends are not permitted } \\
\text { under "substantially similar" provisions. } \\
\text { 14. The Federal Tax Incentive currently } \\
\text { applies only to } 5.7 \%, 7.7 \% \text {, and } 10 \% \\
\text { blends by volume. } \\
\text { 15. Under Replacement Fuel requirements, } \\
\text { a } 20 \% \text { ethanol blend could contribute } 3.3 \% \\
\text { (base case) to the established } 2010 \\
\text { alternative fuel goal. }\end{array}$ & $\begin{array}{l}\text { 11. New EPA waiver needed for blends } \\
\text { ranging from } 17 \text { vol. } \% \text { to } 24 \text { vol. } \% \text {. } \\
\text { 12. Amend existing tax code through } \\
\text { Congress. }\end{array}$ \\
\hline
\end{tabular}

\footnotetext{
${ }^{45}$ Title V of the Energy Policy Act mandates a 30\% replacement of petroleum-based gasoline and diesel fuels by 2010. Assumes EIA's 4.6\% ethanol fuel growth rate (1992-1998) continues through 2010, and the corresponding total transportation ethanol use is 0.326 quads.
} 


\section{References}

Alternative Fuels Data Center, Alternative Fuels Tax Guide for 1997-1998. http://www.afdc.doe.gov.

American Lung Association of Metropolitan Chicago, (no date, possibly 1998). Clearing the Air: 1990-1998. Air Pollution Strategies That Have Worked.

American Petroleum Institute (July, 1988). Alcohol and Ethers: A Technical Assessment of Their Application as Fuels and Fuel Components. API Publication 4261. Second Edition.

American Petroleum Institute (June, 2001). Alcohol and Ethers: A Technical Assessment of Their Application as Fuels and Fuel Components. API Publication 4261. Third Edition.

Amoco Pipeline Co., (1981), Test Study, "Pipelining of Gasohol."

Anchorage General Assembly, (July 12, 1994). A Resolution of the Municipality of Anchorage Recognizing Anchorage as a Carbon Monoxide Non-Attainment Area and Calling for the Use of Ethanol-Based Fuel as a Transportation Control Measure for the Fall and Winter Season of 1994-1995. AR 94-160(S) (as amended).

Andress/Hadder. (November 1998). Factors Affecting the Demand for Ethanol and Motor Fuel.

Archer Daniels Midland. (February 1999). Interview with Carl F. Reeder, Technical Services Consultant.

Archer Daniels Midland, Buckeye Pipeline. (1994). Test Study, "Successful Pipeline Test of Ethanol Blend."

Archer Daniels Midland, Williams Pipeline Company. (1981). Test Study, “Transportation of Ethanol by Commercial Pipeline."

Auto/Oil Air Quality Improvement Research Program (September, 1991). Emissions Results of Oxygenated Gasolines and Changes in RVP.

Auto/Oil Air Quality Improvement Research Program. (July, 1995). Exhaust Emission of E85 Ethanol Fuel and Gasoline in Flexible/Variable Fuel Vehicles. Technical Bulletin No. 16.

Barnes, J. (July 12, 1998). General Motors, Phone Conversation.

Beard, L. (1998). DaimlerChrysler, Phone Conversation. 
Benson, J.D.; Knepper, J.C.; Reuter, R.M.; \& Others. (1995). "Emissions with E85 and Gasoline in Flexible/Variable Fuel Vehicles - The Auto/Oil Air Quality Improvement Research Program." SAE paper \# 952508

BioAlcohol Fuel Foundation, Box 358, SE-891 27 Ornskoldsvik, Sweden, Per Carstedt, Chairman.per.carstedt@ecosystem.se

Brazilian Ethanol Producers' Special Committee Report. (1984).

Broffie, J. EPA. (June 14, 1999). Phone Conversation.

Cagle, G. (May 2, 1999). Colorado Department of Health, Air Pollution Control Division. Phone conversation.

Caldwell, J. EPA. (April 13, 1999). Phone conversation.

California Air Resources Board. http://www.arb.ca.gov.

California Air Resources Board, State of California. (Amended April 25, 2001)

California Procedures Evaluating Alternative Specifications for Phase 3 Reformulated

Gasoline Using the California Predictive Model, page 10,

http://www.arb.ca.gov/cbg/premodel/carfg3pm.doc.

California Air Resources Board. (November, 1998a). Proposed Determination Pursuant to Health and Safety Code Section 43830(g) of the Ozone Forming Potential of Elevated RVP Gasoline Containing 10\% Ethanol.

California Air Resources Board. (November, 1998b). Comparison of the Effects of FullyComplying Gasoline Blend and High RVP Ethanol Gasoline Blend on Exhaust and Evaporative Emissions. [This is Appendix B to CARB 1998a]

California Air Resources Board. (September, 1998c). An Overview of the Use of Oxygenates in Gasoline. Stationary Source Division.

California Air Resources Board. (September 1998). An Overview of the Use of Oxygenates in Gasoline.

California Energy Commission. http://www.energy.ca.gov.

California Energy Commission. (October1998). Supply and Cost of Alternatives to MTBE in Gasoline. Technical Appendices: Ethanol Blending Properties for Task 3 Modeling Work.

California Energy Commission (October, 1998). Staff Report, Supply and Cost of Alternatives to MTBE in Gasoline, Publication No. P300-98-013. 
California Environmental Protection Agency, Air Resources Board. (August 29, 2001). Workshop Regarding Regulatory Fuels Activities.

Center for Petroleum and Petrochemical Professionals. http://www.petrochem.net.

Chemical Economics Handbook. (1994). Menlo Park, CA.: SRI International.

Clean Fuels Development Coalition, Oxygenated Fuels Association, and Others. (July,1997). History and Overview of the Reformulated Gasoline Program: A Briefing Book for Members of Congress and Staff.

Council of Great Lakes Governors (July 26, 1993). Comparison of the Air Quality Effects of Ethanol and MTBE in Reformulated Gasoline in the Lake Michigan Region. Final Report.

David Andress \& Associates, Inc. (November, 1998, Factors Affecting the Demand for Ethanol as a Motor Fuel.

DeLucchi, M. (November 1997). "A Revised Model of Emissions of Greenhouse Gases for the Use of Transport: Fuels and Electricity." UCD-ITS-RR-97-22. Institute of Transportation Studies, University of California. Davis.

Gallagher, P.; Otto, D.; Dikeman, M.; Economics Department Iowa State University, Ames, Iowa. (November, 1998). "Effects of an Oxygen Content Proposal for Fuel in Midwest Ethanol Markets and Local Economies," A Report to the Iowa Corn Promotion Board and The Iowa Farm Bureau Federation.

Energy Information Administration. http://www.eia.doe.gov.

Energy Information Administration. (December, 1997). Alternatives to Traditional Transportation Fuels 1996. DOE/EIA-0585(96).

Energy Information Administration. (December, 1999). Annual Energy Outlook 1999, with Projections to 2020. DOE/EIA-O383(99). U.S. Department of Energy.

Energy Information Administration. (August 19, 1998). Areas Participating in the Oxygenated Gasoline Program. U.S. Department of Energy. Http://www.eia.doe.gov/emeu/steo/pub/special/oxy2.html.

Environmental Protection Agency. (April, 1995). Is Reformulated Gasoline a "New" Gasoline? EPA 420-F-95-007. Office of Mobile Sources.

Environmental Protection Agency. (March 29, 1999). State Winter Oxygenated Fuel Programs. Office of Mobile Sources. 
Equiva Services, LLC, (January, 1999). Letter to Missouri Department of Natural Resources on behalf of Equiva Wood River Refinery.

Faiz, A.; Weaver, C. S.; and Walsh, M.P. (1990). Air Pollution from Motor Vehicles, Standards and Technologies for Controlling Emission, The World Bank, 1996.

Fuel Reformulation. (no date, possibly 1995). ETBE, Environment + Energy + Economy, Meeting the Challenging Needs of Today. Issue Brief No. 2. Fuel Reformation Supplement.

Gardiner, D.(June 24, 1999). Thermotech Engineering Division, Nexum Research Corporation. Phone conversation.

Governors' Ethanol Coalition, (1999). Letter to U.S. Environmental Protection Agency Administrator, Carol Browner, January.

Governors' Ethanol Coalition. http://ethanol-gec.org.

Guerrieri, D.A., Caffrey, P. J., \& Rao, V. (1995). "Investigation into the Vehicle Exhaust Emissions of High Percentage Ethanol Blends.” SAE Technical Paper Series, \# 950777.

Gushee, D. (1996). Alternative Transportation Fuels and Clean Gasoline: Background and Regulatory Issues. Congressional Research Service. Updated January 17, 1996.

Huff, S. (December 19, 2001). Oak Ridge National Laboratory, Peer Review Comments.

Iowa Department of Natural Resources, Energy Bureau.

http://www.state.ia.U.S./dnr/energy.

Iowa State University. (November, 1998). Effects of an Oxygen Content Proposal for Fuel in Midwest Ethanol Markets and Local Economies.

Katzen, R.; Madson, P. W.; and Monceaux, D. A. (1997). "Biomass-Derived Ethanol and ETBE in Motor Fuels," Raphael Katzen Associates International, Cincinnati, Ohio.

Keller, A.; Froines, J.; Koshland, C.; Reuter, J.; Suffect, I. M.; and Last, J. (November, 1998). Health \& Environmental Assessment of MTBE. Report to the Governor and Legislature of the State of California as Sponsored by SB 521, Vol. I, Summary \& Recommendations.

Kelly, K.; Eudy, L.; Coburn, T. (June 1999). "Light-duty Alternative Fuel Vehicle: Federal Test Procedure Emission Results.” NREL. Pub \# TP-540-25818.

Kelly, K. J.; Beiley, B.K.; Coburn, T.C.; Clark, W.; Lissiuk, P. (May, 1996). "Federal Test Procedure Emissions Test Results from Ethanol Variable-Fuel Vehicle Chevrolet Luminas.” SAE Paper \#961092. 
Livo, K. (April 18, 1999). Colorado Department of Health, Air Pollution Control Division. Phone conversation.

Lugar, R. G. and Woolsey, R. J. (1999). The New Petroleum. Foreign Affairs, January/February.

Minnesota Department of Agriculture. (February, 1999). Letter to Senator Ed Schrock.

Minnesota Office of Legislative Auditor. (February, 1997). "Ethanol Programs: A Program Evaluation." Report \#97-04.

Minnesotans for an Energy Efficient Economy's Sustainable Minnesota, Ethanol and Biofuels Resources. http://me3.org

Missouri Department of Natural Resources, (1999). Proposed Rule, 10 CSR 10-5.446 Gasoline Oxygen Content Requirements.

Mueller Associates, Inc. (1988). "Status of Alcohol Fuels Utilization Technology for Highway Transportation: A 1986 Perspective," ORNL/Sub/85-22007/4.

Myron, William B, et.al. (August, 1985). Colorado Department of Health, Air Pollution Control Division, Ethanol Blended Fuel as a CO Reduction Strategy at High Altitude, 2 vol.

Nastari, Dr. P. M., (1998). Fuel Ethanol in the $21^{\text {st }}$ Century Seminar, "The Brazilian Fuel Ethanol Experience", April.

Nastari, Plinio M. (October, 1995). "Sustained Economic Development Through the Use of Biomass Fuels: The Case of Ethanol in Brazil.” World Energy Council Paper.

National Association of State Energy Officials. http://www.naseo.org.

National Corn Growers Association. http://www.ncga.com.

National Corn Growers Association (September 22, 1988). Letter from John W. McClellan to Mr. Peter Venturini of CARB.

National Renewable Energy Laboratory. (September, 1999). "Light-Duty Alternative Fuel Vehicles: Federal Test Procedure Emission Results.” NREL/TP-540-25818.

Nebraska Ethanol Board. http://nebsspc.nrc.state.ne.U.S./.

Nylund, N.O. (Technical Research Center of Finland). (1986) "Engine Wear with Alcohol Fuels in Nordic Conditions," Seventh International Symposium on Alcohol Fuels, Paris , France, October $20-23,1986$. 
Office of the Legislative Auditor, State of Minnesota. (February, 1997). Ethanol Programs: A Program Evaluation Report. Report \#97-04.

Pace Consultants Inc. (November, 1998). "Analysis and Refinery Implications of EthanolBased RFG Blends under the Complex Model Phase II." Prepared for Renewable Fuels Association.

Pitstick, M. E. (1993). "Emissions from Ethanol and LPG Fueled Vehicles." AN/ES/CP78570. Argonne National Laboratory.

Potter, F.I., (1994). “RFG Quality Improves With ETBE," Fuel Reformulation, July/August, p.1.

Renewable Fuels Association. (September 4, 1998). Letter from Bob Dinneen to Peter Venturini, $C A R B$.

Rhoad, T. (1999). Ford Motor Company, Phone conversation.

Reynolds, B. (October 19, 1999), Downstream Alternatives, Inc. E-mail communication.

Schlanger, M. O., (1994). "The Oxygenated Fuels Program Attempting to Snatch Defeat from the Jaws of Victory. Use Demonstrated Science to Meet Clean Air requirements," Fuel Reformulation, July/August, pp. 38-40.

Schremp, G. California Energy Commission. (2001). "California Issues-Expanded Use of Ethanol and Alkylates." LLNL Workshop, Oakland, CA, April 10 - 11. 2001.

Shepard, B., Environmental Specialist, Alaska Department of Environment Conservation. (January 27, 1999). E-mail; telephone communication.

Sinor, J. E. Bailey, B. K. (1993). "Current and Potential Future Performance of Ethanol Fuels.” SAE Technical Paper 930376, International Congress and Exposition, Detroit, Michigan.

State of Minnesota. (February 1997). Office of Legislative Auditor Ethanol Programs: A Program Evaluation.

Sopata, J. EPA. (May 27, 1999). Phone conversation.

Systems Applications International, Renewable Fuels Association, TSS, California Renewable Fuels Council, Parallel Products, and Arkenol (November 9, 1998). Joint Letter to the Honorable John Dunlap, III.

Szwarc, A. ADS Technology and Sustainable Development. (July 26, 1999). E-mail. State of California, (March, 1999). Governor Gray Davis, Executive Department, Executive Order D-5-99. 
Testimony of Margo Oge. (September, 1998). Director of Office of Mobile Source, Office of Air and Radiation, U.S. EPA, before the Committee on Environment and Public Works, United States Senate.

The PACE Consultants, Inc. (November, 1998). Analysis and Refinery Implications of Ethanol-Based RFG Blends Under the Complex Model Phase II. Prepared for Renewable Fuels Association.

U.S. Department of Energy. (July, 1997). Replacement Fuel and Alternative Fuel Vehicle Technical And Policy Analysis, pursuant to Section 506 of the Energy Policy Act of 1992. Office of Transportation Technologies.

Wang, M.; Saricks, C.; Santini, D. (1998) Fuel Cycle Energy and Greenhouse Gas Emission Effects of Ethanol. Argonne National Laboratory.

Williams Energy Company. http://www.williamsenergy.twc.com.

Williams Pipeline Company. (February, 1999), Interview with Ron Miller, V.P. Ethanol Marketing and Bio-Products.

Wyman, C.E. (1996). Handbook on Bioethanol: Production and Utilization. Edited by Charles E. Wyman.

Yancey, M. (1999). National Renewable Energy Laboratory, phone conversation. 


\section{Appendix A Technical Issues}




\section{E85 Fuel Systems}

As a point of contrast, it is useful to discuss the differences between an ethanol flexible fuel vehicle (FFV) E-85 fuel control system and a conventional system. E85 vehicles are equipped with upgraded fuel systems with a larger fuel pump to enable them to pump more fuel to achieve the same energy content as in a comparable conventional gasoline vehicle (Cagle 1999). The injectors are also sized to accommodate the increased fuel volume requirement. The fuel tanks and lines near the tank are composed of either stainless steel or some other metal, and the other fuel system materials are made from a harder polymer.

In the Ford FFV E85 vehicle, the fuel system is augmented by a fuel composition sensor, (located upstream on the fuel system before the fuel injectors). The sensor is used to accurately detect the amount of ethanol in the fuel, which enables the fuel control system to make initial adjustments regarding fuel delivery. Also, in an effort to compensate for the cooler burning temperatures of ethanol (thereby delaying the catalyst light-off), an oxygen catalyst is placed close to the exhaust ports. Due to its proximity to the exhaust ports, the oxygen catalyst lights-off faster, and serves to initially control cold-start emissions before the larger, three-way catalyst lights-off further downstream (Rhoad 1999).

Rhoad also reported that during preliminary testing to support Low Emission Vehicle (LEV) certification for the Year 2000 Ford Taurus E85 vehicle, it was noted that placing the oxygen catalyst as close as possible to the exhaust port could possibly curtail the life of the catalyst. Other fuel system components could also be affected. 


\section{Appendix B Emissions and Emissions Testing}




\section{California Air Resources Board Twelve-Vehicle Emissions Testing Program}

The California reformulated gasoline (CaRFG) regulations, which became effective in March 1996, limit the Reid Vapor Pressure (RVP) of summertime gasoline to 7.0 psi and impose an oxygen cap of 3.5 wt. $\%{ }^{46}$ In the past, the oxygen cap was $2.7 \%$, which limited the amount of ethanol blended into gasoline to about $7.7 \%$ by volume. This prevented the use of $10 \%$ ethanol blend in the California RFG market. To afford refiners and blenders more flexibility in formulating reformulated gasoline (RFG), the California Air Resources Board (CARB) considered and approved a staff proposal to raise the oxygen cap from 2.7 wt. \% to 3.5 wt. \%, allowing ethanol blending to 10 vol. $\%$.

However, the CARB study found that there is a likelihood of between $90 \%$ and $100 \%$ that emissions of nitrogen oxides $\left(\mathrm{NO}_{\mathrm{x}}\right)$, total hydrocarbons (THC), toxics, and potency weighted toxics are greater with the high RVP $10 \%$ ethanol blend than with the fully complying gasoline. It also found that the likelihood is greater than $95 \%$ that the ozone forming potential is higher with the high RVP ethanol blend than with the fully complying gasoline. In contrast, for carbon monoxide (CO), the likelihood is almost $100 \%$ that emissions are higher with the fully complying gasoline than the RVP ethanol blend (CARB, 1998a, p. 4). This section describes the nature of the CARB emissions testing in relation to the $10 \%$ ethanol blend, explains the test results, and discusses the implications.

\section{Description of the CARB Emissions Testing}

The test program involves 12 vehicles in the 1990 through 1995 model year: 1990 Honda Accord and Integra, 1991 Ford Explorer and Chrysler Caravan, 1992 GM Cutlass and Toyota Lexus, 1993 Mazda MPV and Ford Escort, 1994 Toyota Camry and Nissan Sentra, and 1995 Nissan Pathfinder and GM Grand AM. ${ }^{47}$ For emissions control systems, all vehicles were equipped with a 3-way catalytic converter, multi-point fuel injection, and regular or heated oxygen sensors. Some have exhaust gas re-circulation or warm-up 3-way catalytic converters. These models encompass emissions control systems that were typical in at least 50\% of the on-road fleet in California in 1996.

All 12 vehicles were tested for exhaust emissions on federal test procedure (FTP) and on REP05 (off-cycle) test procedure for driving at high speeds. Six vehicles were tested for evaporative emissions based on CARB's procedures for the 2-day diurnal and standard 1hour hot-soak tests. Running loss emissions were estimated using a CARB draft evaporative emissions model and EPA's evaporative emissions model.

The two gasoline blends compared in the CARB study were derived by blending 10 vol. $\%$ ethanol and 11 vol. \% methyl tertiary butyl ether (MTBE), with the same gasoline base. ${ }^{48}$ The MTBE blend is regarded as fully complying with the cleaner burning

\footnotetext{
${ }^{46}$ This is in terms of "cap limit," not flat limit. In terms of the flat limit, then the cap is $2.2 \mathrm{wt} . \%$.

${ }^{47}$ Actually, 14 vehicles were tested, but two were excluded due to various testing and data validity problems. For an explanation of such problems, see CARB 1998b, p.9.

${ }^{48}$ For a description of the 12 vehicles tested, see Appendix B, pg. B-2.
} 
gasoline requirements for summer months in California. The primary differences between the two test blends were in terms of oxygen content and RVP. The target oxygen context was set between 1.8 and $2.2 \mathrm{wt}$ \% for the fully complying blend and between 3.2 and 3.6 wt. \% for the ethanol blend. For RVP, the targets were in the range of 6.7 - 7.0 and 7.7 $8.0 \mathrm{psi}$, respectively, for the complying blend and ethanol blend. The other aspects of the composition of these two test fuels are shown in Table B-1. 


\section{Table B-1 Composition of Test Fuels in CARB's High RVP 10\% Ethanol Blend Study}

\begin{tabular}{|l|c|c|c|c|c|c|}
\hline \multirow{2}{*}{ Property } & \multicolumn{2}{|l|}{ Ethanol Blend } & \multicolumn{2}{l|}{ MTBE } \\
\cline { 2 - 7 } & Target & $\begin{array}{l}\text { Blender's } \\
\text { Analysis }\end{array}$ & $\begin{array}{l}\text { ARB's } \\
\text { Average* }\end{array}$ & Target & $\begin{array}{l}\text { Blender's } \\
\text { Analysis }\end{array}$ & $\begin{array}{l}\text { ARB's } \\
\text { Average }^{*}\end{array}$ \\
\hline Oxygen (wt \%) & $3.2-3.6$ & 3.5 & 3.94 & $1.8-2.2$ & 1.97 & 2.09 \\
\hline Aromatic (vol \%) & $23.0-25.0$ & 23.7 & 26.46 & $23.0-25.0$ & 23.0 & 23.39 \\
\hline Olefins (vol \%) & $4.0-6.0$ & 4.9 & 5.17 & $4.0-6.0$ & 4.4 & 5.20 \\
\hline Benzene (vol \%) & $0.5-1.0$ & 0.8 & 0.82 & $0.5-1.0$ & 0.8 & 0.81 \\
\hline RVP (psi) & $7.7-8.0$ & 8.0 & 7.81 & $6.7-7.0$ & 7.0 & 6.88 \\
\hline T10(deg F) & $130-140$ & 133 & 129 & $130-140$ & 139 & 134 \\
\hline T50 (deg F) & $190-210$ & 195 & 186 & $190-210$ & 199 & 197 \\
\hline T90 (deg F) & $280-300$ & 297 & 297 & $280-300$ & 297 & 296 \\
\hline Sulfur (ppmw) & $30-40$ & 30.30 & 33.19 & $30-40$ & 30.31 & 31.76 \\
\hline
\end{tabular}

* Only CARB analytical results were used to calculate the average. Where replicates samples were taken, the mean was used for the analysis. It should be noted that none of the differences between the blender's and the CARB's results were greater than the reproducibility for each applicable test method and are not considered significant.

Source: CARB, Comparison of the Effects of A Fully-Complying Gasoline Blend and A High RVP Ethanol Gasoline Blend on Exhaust and Evaporative Emissions. November 1998, Table 3, page 8 .

Duplicate back-to-back exhaust and evaporative tests were conducted on all vehicles for each fuel type. Because of the fact that it is difficult to purge ethanol from the canister, the fully complying fuel type was tested on all vehicles first and then the higher RVP ethanol blend was tested on all vehicles. To the extent possible, the same driver, same dynamometer, and same evaporative test enclosure were used.

The exhaust and evaporative emissions measured in the test include $\mathrm{CO}, \mathrm{NO}_{\mathrm{x}}, \mathrm{THC}$, nonmethane hydrocarbon (NMHC), non-methane organic gases (NMOG), carbon dioxide $\left(\mathrm{CO}_{2}\right)$, ozone forming potential (OFP), ozone forming potential plus carbon monoxide (OFPCO), sum of toxics masses (TOX), and potency-weighted toxics (TOXPW). The four compounds under toxics are benzene, 1,3-butadiene, formaldehyde, and acetaldehyde.

Arithmetic averages and a more formal statistical methodology were used to evaluate the test results. For individual test modes, percent changes in emissions were computed using the results of the complying blend as the denominator. The overall percentage change in emissions (the combined effects of exhaust and evaporative processes) was calculated, based on the percent of the means and mean of percents as well as the formal statistical evaluation. 


\section{Test Results}

The results of the emissions tests and analysis are summarized in Table B-2. Some highlights according to the formal statistical method:

- For exhaust emissions only, $\mathrm{CO}$ emissions are about $10 \%$ lower for the high RVP ethanol blend, compared to the fully complying blend. In contrast, $\mathrm{NO}_{\mathrm{x}}$ emissions are $14 \%$ higher; THC and NMOG each is $3 \%$ higher for the high RVP ethanol blend. These results were not affected by assumption about the differences in running loss.

- For evaporative emissions only, emissions of THC and NMOG are, respectively, about $52 \%$ and $83 \%$ higher for the high RVP ethanol blend, compared to the fully complying blend, if the difference in running loss is assumed to be non-zero. In contrast, if difference in running loss is assumed to be zero, the corresponding percentages are $25 \%$ and $32 \%$, respectively, for THC and NMOG.

- For combined exhaust and evaporative emissions, with non-zero running loss difference, THC emissions are 18\% and NMOG emissions $32 \%$ higher for the high RVP ethanol blend compared to the fully complying blend. With zero running loss differences, the combined exhaust and evaporative emissions are lower- $10 \%$ for THC and $14 \%$ for NMOG.

- Without considering the impacts on $\mathrm{CO}$, the ozone forming potential of the combined exhaust and evaporative emissions is $21 \%$ higher for the ethanol blend when running loss is assumed to be non-zero. This is largely due to the higher RVP of the ethanol blend, resulting in significantly greater evaporative NMOG mass emissions. If running loss difference is assumed to be zero, the ozone-forming potential is about $9 \%$ higher for the elevated RVP ethanol blend. 


\section{Table B-2 Percent Change in Emissions of Elevated RVP Ethanol Blend Compared to Complying Blend*}

(Positive Number Indicates an Emissions Increase for the Elevated RVP Ethanol Blend)

\begin{tabular}{|c|c|c|c|c|c|c|}
\hline Pollutant & \multicolumn{3}{|c|}{ Analysis Method } & \multicolumn{3}{|c|}{ Analysis Method } \\
\hline & $\begin{array}{l}\% \text { of } \\
\text { Means }\end{array}$ & $\begin{array}{l}\text { Mean of } \\
\% \text { s }\end{array}$ & $\begin{array}{l}\text { Formal } \\
\text { Method }\end{array}$ & $\%$ of Means & $\begin{array}{c}\text { Mean of } \\
\% \mathrm{~s}\end{array}$ & $\begin{array}{l}\text { Formal } \\
\text { Method }\end{array}$ \\
\hline & \multicolumn{3}{|c|}{ Running Loss Diff $=$ Zero } & \multicolumn{3}{|c|}{ Running Loss Diff $=$ Non Zero } \\
\hline Exhaust Only & & & & & & \\
\hline $\mathrm{CO}$ & $-7 \%$ & $-7 \%$ & $-10 \%$ & $-7 \%$ & $-7 \%$ & $-10 \%$ \\
\hline $\mathrm{NO}_{\mathrm{x}}$ & $17 \%$ & $16 \%$ & $14 \%$ & $17 \%$ & $16 \%$ & $14 \%$ \\
\hline Total Hydrocarbons & $8 \%$ & $5 \%$ & $3 \%$ & $8 \%$ & $5 \%$ & $3 \%$ \\
\hline Non-methane Organic Gases & $8 \%$ & $7 \%$ & $3 \%$ & $8 \%$ & $7 \%$ & $3 \%$ \\
\hline \multicolumn{7}{|l|}{ Evaporative Only } \\
\hline Total Hydrocarbons & $27 \%$ & $26 \%$ & $25 \%$ & $55 \%$ & $54 \%$ & $52 \%$ \\
\hline Non-methane Organic Gases & $32 \%$ & $14 \%$ & $32 \%$ & $82 \%$ & $84 \%$ & $83 \%$ \\
\hline \multicolumn{7}{|l|}{$\begin{array}{l}\text { Exhaust and Evaporative } \\
\text { Combined } * *\end{array}$} \\
\hline Total Hydrocarbons (69/31) & $14 \%$ & $13 \%$ & $10 \%$ & $23 \%$ & $21 \%$ & $18 \%$ \\
\hline $\begin{array}{l}\text { Non-methane Organic Gases } \\
(64 / 36)\end{array}$ & $17 \%$ & $9 \%$ & $14 \%$ & $35 \%$ & $35 \%$ & $32 \%$ \\
\hline $\begin{array}{l}\text { Ozone Forming Potential } \\
\text { without CO }(73 / 27)\end{array}$ & $11 \%$ & $11 \%$ & $9 \%$ & $20 \%$ & $23 \%$ & $21 \%$ \\
\hline $\begin{array}{l}\text { Ozone Forming Potential with } \\
\mathrm{CO}(76 / 24)\end{array}$ & $8 \%$ & $8 \%$ & $6 \%$ & $16 \%$ & $19 \%$ & $17 \%$ \\
\hline Toxic $(83 / 17)$ & $13 \%$ & $11 \%$ & $9 \%$ & $18 \%$ & $15 \%$ & $13 \%$ \\
\hline Potency Wt.ed Toxics $(84 / 16)$ & $5 \%$ & $4 \%$ & $1 \%$ & $9 \%$ & $6 \%$ & $5 \%$ \\
\hline
\end{tabular}

* Exhaust emissions consist of FTP and REP05 weighted according to the fraction of daily driving associated with each cycle, based on a U.S. EPA study. Evaporative emissions consist of hot soak, diurnal and running loss weighted according to Motor Vehicle Emission Inventory Version 7G (MVEI7G) fractions. Running loss emissions estimated based on CARB's MVEI and U.S. EPA evaporative model.

** Weighted proportion of exhaust emissions to evaporative emissions shown in parentheses.

Sources: CARB, Proposed Determination Pursuant to Health and Safety Code Section 43830(g) of the Ozone Forming Potential of Elevated RVP Gasoline Containing $10 \%$ Ethanol, November, 1998, Table IV-1, page 19.

- When CO is included, and assuming non-zero running loss difference, the ozone forming potential is $17 \%$ higher for the high RVP ethanol blend than for the complying blend. When running loss difference is assumed to be zero, the corresponding ozone-forming potential is $6 \%$ higher for the elevated RVP ethanol blend.

- The combined emissions of toxics (benzene, 1,3-butandiene, formaldehyde, and acetaldehyde emissions) are $13 \%$ or $9 \%$ higher, respectively, for the non-zero and zero running loss difference cases. 
- The combined potency weighted toxics are $5 \%$ or $1 \%$ higher, respectively, for the non-zero and zero running loss difference cases.

\section{Issues in Staff Proposal}

The following parties have taken issue with aspects of the CARB staff analysis and recommendation:
Arkenol
Californians Against Waste
California Department of Food and Agriculture
California Public Interest Research Group
California Renewable Fuels Council
California Rice Industry Association
Clean Water Action
Communities for a Better Environment
National Audubon Society
National Corn Growers Association
Parallel Products
Renewable Fuels Association (RFA)
Silicon Valley Toxics Coalition
South Tahoe Public Utility District
Systems Applications International, Inc
TSS

In the following discussion, the issues are listed first and then briefly explained. CARB staff's responses are also summarized.

Issue: The number of vehicles included in the test program is limited, raising questions as to the adequacy of the test program, the variability of the data observed, and the statistical significance of the results.

\section{Issue: There is a lack of data on high-emitting vehicles.}

Issue: The types of vehicles included in the program accounted for a small part of the vehicle emissions in California.

The above issues are grouped together because some of the arguments regarding them are related. The CARB test program involved only 12 vehicles, resulting in only 56 data points, less than 7/10ths of one percent of the data points in the California Predictive Model. Only six of the 12 vehicles were used in the evaporative tests. In addition, the 12-vehicle test was supposed to be only Phase I of a two-phase, 125-vehicle test program. Analysis of the Phase I data helped to pinpoint the needed improvements for inclusion in Phase II of the test program. Since high-emitting vehicles and older vehicles are not included in the 12 vehicle test, the test results accounted for less than $10 \%$ of the total VOC emissions from 
light-duty vehicles in California. The small sample size and the lack of high-emitting and older vehicles raised questions about how representative the 12 vehicles tested were and the statistical significance of the results measured and described in the staff report. Hence, the CARB should defer making a finding and direct staff to proceed to complete Phase II of the study.

\section{Staff Conclusions and Recommendations}

According to CARB staff, the above results indicated that the elevated RVP ethanol blend significantly increases overall emissions of $\mathrm{NO}_{\mathrm{x}}, \mathrm{THC}, \mathrm{NMOG}$, ozone forming potential, toxics, and potency weighted toxics, and decreases emissions of CO compared to the fully complying blend of reformulated gasoline. Because such results are highly significant, CARB staff suggested that additional testing with 1990-1995 model-year vehicles was not necessary.

From the above results and the collaborating results summarized in staff's proposed determination (CARB 1998a, pp. 22-30), it was recommended that CARB find that reformulated gasoline containing 10\% ethanol with 1 psi higher RVP has higher ozone forming potential than the fully complying blend. As per the December 11, 1998, ruling, this finding eliminates the conditional RVP exemption in California's Health and Safety Code section 43830(g) for gasoline containing 10\% ethanol (California Air Resources Board 1998). However, as mentioned previously, the December ruling also directed that a comprehensive review of the clean-burning gasoline program would take place to identify "new ways to utilize ethanol."

CARB Staff Response: The CARB 12-vehicle test program is the most extensive speciated exhaust and evaporative emissions data set collected to date. Even in the widely cited auto/oil test programs involving over $\$ 40$ million, many test programs included only 10 to 29 vehicles, depending upon individual test programs. Staff believes that the CARB test program is adequate for making a determination with respect to HSC section 43830(g). Further, the Ethanol Workgroup, which included representatives from the Renewable Fuels Association and other ethanol industry people, had reviewed design and protocols of the test program.

According to Staff's assessment, the vehicle types tested in the 12-vehicle program account for about $32 \%$ of the reactive organic gas emissions, $42 \%$ of the $\mathrm{CO}$ emissions, and $48 \%$ of the $\mathrm{NO}_{\mathrm{x}}$ emissions in the light-duty emissions inventory for 1998. Since the vehicles tested are equipped with 3-way catalysts and fuel injection which are installed in 1986 or newer model year vehicles, Staff estimated that the type of vehicles tested accounted for about $70 \%$ of vehicle miles traveled in California in 1998.

High-emitting vehicles generally have faulty emission control systems and are not considered in the test program for two reasons. First, emissions from such vehicles from the same fuel are highly variable from test to test, making it difficult to detect the fuel effect on emissions. Second, the time and resources required to conduct such a test on such high-emitting vehicles are thought to be excessive. In addition, in Staff's view, there is 
strong evidence that older vehicles respond to oxygen and RVP in the same way as the test fleet and tend to increase in the ozone forming potential from elevated RVP gasoline containing ethanol (CARB, 1998a, p. 32). RFA disputed this claim and stated that data points within the California Predictive Model "show a clear and statistically significant response to oxygen the higher the emission level per car." (Systems Applications International, et. al. 1998. Joint Letter to the Honorable John Dunlap, III. November 9.) With respect to the design of the test program, Staff stated that, from the very beginning, it was recognized that the results of Phase I testing would allow a decision on the necessity of additional testing and, if so, what changes to the test protocols need to be made. In this case, Staff has decided from the test results and other collaborating evidence, that further testing is not necessary.

Issue: Sequencing of tests on the elevated RVP ethanol blend gasoline and the fully complying blend was not randomized.

In the 12-vehicle test program, the MTBE blend was always tested before the $10 \%$ ethanol blend for each vehicle. While this was necessitated by the difficulty in purging ethanol from the canister, with its potential for confounding the test results, the issue of how nonrandomness of the test procedure would affect the test results needs to be explored in Phase II of the test program. Otherwise, there would be no assurance that the test results are not affected by driver bias. In addition, the question of the adequacy of preconditioning may be raised. (Renewable Fuels Association, 1998; National Corn Growers Association, 1998)

CARB Staff Response: This issue was fully discussed with the Ethanol Workgroup both before and after the conduct of the test program. It was agreed that this was the only practical way of doing the test. Nevertheless, the NCGA pointed out that such agreement would not obviate the need for randomization. Otherwise there may be bias as the driver becomes familiar with the vehicle.

Issues: Using THC data in lieu of NMOG as the basis of analysis.

RFA and its consultant, SAI, argued that use of THC in places where NMOG should be used tends to bias the analysis result because the average exhaust NMOG emissions are somewhat less than the average exhaust THC.

CARB Staff Response: In its analysis, CARB did use the relationship OFP/NMOG. However, the relationship was further adjusted by using the THC weighting factors (NMOG/THC) from the Motor Vehicle Emissions Inventory (MVEI). The results are shown as OFP/THC. This is not the same as directly using the relationship of OFP/THC.

Issue: Studies using Urban Airshed Modeling (UAM) that show the equivalency in ozone forming potential between ethanol and MTBE were not cited. UAM modeling should be used in the emission testing.

Renewable Fuels Association and others in the ethanol industry claimed that the consensus of the Ethanol Workgroup is that the Urban Airshed Modeling (UAM) studies are the most 
appropriate means of assessing the ozone forming potential of emissions from different fuel blends. There were studies, including UAM, which demonstrated the equivalence between ozone forming potential ethanol and that of MTBE. An example is the 1993 Council of Great Lakes Governors study, entitled Comparison of the Air Quality Effects of Ethanol and MTBE in Reformulated Gasoline in the Lake Michigan Region. Staff has ignored such studies in its proposal regarding the 1 psi exemption of elevated RVP ethanol blend (Systems Applications International, et. al. 1998).

CARB Staff Response: Urban airshed models were not used because of the requirements of the HSC Section 43830(g). Staff believes that the law requires CARB to make its determination of the ozone forming potential of an elevated RVP ethanol blend and that of a fully complying blend based on independently verifiable automobile exhaust and evaporative emissions tests performed on a representative fleet of vehicles. The law also requires that the comparison be based on the total emissions for each fuel, excluding oxides of nitrogen, on the same fleet of vehicles. Staff used the Carter maximum incremental reactivity values to account for relative reactivity. Such values have been approved by CARB for use in test procedures such as this one. The results of Staff analysis showed that there was a significant increase in ozone forming potential in the elevated RVP ethanol blend, compared to the fully complying blend. In addition, if the results were evaluated using UAM, Staff expects that the analysis would also demonstrate a significant increase in OFP for the $10 \%$ ethanol blend.

Issue: The benefits of lower CO emissions for the 10\% ethanol blend, the VOC-like contribution to $C O$, should be taken into consideration.

Issue: Different weighting factors should be used for combining exhaustive and evaporative emissions.

RFA argued that $\mathrm{CO}$ emissions should be treated as a VOC-like precursor to ozone formation. Since the $10 \%$ ethanol blend showed lower CO emissions than the MTBE blend, there is an offset to ozone forming potential that should be taken into consideration. When such benefits are included, the difference in ozone forming potential of the elevated RVP ethanol blend and of the MTBE blend will be reduced and the statistical equivalence of those two fuel blends in terms of ozone forming potential can be demonstrated. On behalf of RFA, Systems Applications International (SAI) applied alternative calculations, giving credits to lower $\mathrm{CO}$ emissions and using different weighting factors, and demonstrated substituting ethanol for MTBE would not raise the ozone forming potential.

CARB Staff Response: In the process of replicating the SAI analysis, Staff found that SAI used certain logic and math which gave exaggerated weight to exhaust emissions. Staff regards some of the assumptions made by SAI as faulty. For example, SAI relied on the ratio of $\mathrm{CO} / \mathrm{NMOG}$ in the test data, while Staff relied on the ratio of CO/NMOG from MVEI17G, to account for the contribution of CO to ozone formation. The SAI analysis showed that $30 \%$ of exhaust ozone is from CO, while the CARB analysis showed $15 \%$. When such faulty assumptions and procedures are corrected, the overall increase in ozone forming potential of the $10 \%$ ethanol blend over the MTBE blend is raised from SAI's $0 \%$ 
to $4 \%$, compared to CARB staff's $6 \%$, assuming the running loss difference is zero. If running loss difference is assumed to be non-zero, the adjusted SAI figure for change in ozone forming potential is $+14 \%$, compared to Staff's $+17 \%$.

Issue: The broader aspects of a reformulated gasoline program, particularly with respect to existing and growing contamination of drinking water supply by MTBE, compared to ethanol, should be considered.

As an oxygenate in reformulated gasoline, MTBE has been the choice of refiners and blenders because of its blending properties and low cost. Recently, however, MTBE has been detected in groundwater and, at some levels of concentration, it is believed to be a public health risk. In South Tahoe Public Utility District, 35\% of the wells are closed, and $17 \%$ of water production has been lost. In contrast, ethanol is known to be "non-persistent, non-mobile, and non-toxic in soil and water." In addition, there are vast quantities of agricultural and other waste resources that can be converted into ethanol. Thus, there is a need to determine how ethanol can be more broadly used in California without incurring additional pollution.

CARB Staff Response: The Staff did not address this issue directly. Indirectly, Staff pointed out that in the Spring of 1998, CARB started to consider how to provide additional compliance flexibility to meet the California reformulated gasoline requirement. Staff presented to the Board proposals to raise the oxygen cap to $3.5 \mathrm{wt} . \%$ and to rescind the wintertime oxygen content requirement in the Federal $\mathrm{CO}$ attainment areas.

As discussed in the chapter on regulatory and policy issues, CARB adopted the proposal to rescind the winter oxygen requirement in CO attainment areas on August 27, 1998. Further, CARB adopted the 3.5 wt \% oxygen cap on December 11, 1998. 


\section{Appendix C Regulatory and Policy Issues}




\section{Federal Reformulated Gasoline Requirements}

Starting in January 1995, the CAAA required that RFG be sold in the nine worst ozone non-attainment cities. The nine cities are Baltimore, Chicago, Hartford, Houston, Los Angeles, Milwaukee, New York, Philadelphia, and San Diego. Other ozone non-attainment areas can opt-in to the program as air pollution control strategies become more defined and as RFG supplies become more abundant.

The RFG program went into effect on January 1, 1995. The program applies on a yearround basis, and is intended for metropolitan control areas with severe ozone pollution. The program aims to reduce smog and year-round air toxics by decreasing fuel volatility, reducing benzene, aromatics, and other toxic substances in gasoline, and by adding oxygenates to achieve more complete combustion in the engine. To reduce gasoline volatility, RVP standards are set. The program is implemented in two phases.

- Phase I was completed in December, 1999. The reformulated gasoline program succeeded in lowering emissions by exceeding the Phase I requirements (Clean Fuels Development Coalition, \& Others [1997]). For example, in 1995, actual reduction of VOCs was over $28 \%$, compared to the $15 \%$ requirement in the Phase I. Similarly, actual reduction of air toxics was $17 \%$, compared to Phase I's $15 \%$. In addition, there was a $2 \%-3 \%$ reduction in $\mathrm{NO}_{\mathrm{x}}$, compared to $0 \%$ of Phase I requirements.

- In Phase II (January 1, 2000 and beyond), the RFG must reduce VOCs by at least 25\%, $\mathrm{NO}_{\mathrm{x}}$ by $4 \%$ to $7 \%$, and air toxic emissions by $20 \%$. The composition of the RFG is as follows:

Minimum oxygen content: $2 \%$ by weight.

$>$ RVP is a performance-based standard. Approximately 6.7 psi is expected for both Northern and Southern areas for the summer. In the winter, it can be up to 15 psi for both Northern and Southern areas.

$>$ Benzene: $1.0 \%$ by volume.

$>$ Aromatics: $25 \%$ by volume.

$>$ Sulfur limit is $140 \mathrm{ppm}$.

\section{Federal Winter Oxygenates Requirement}

The wintertime $\mathrm{CO}$ reduction provisions of the CAAA began in 1992, requiring a minimum $2.7 \mathrm{wt}$ \% oxygen. Some areas have changed the control period for winter oxygenates. Some shortened it while others lengthened it. For example, the State of Colorado received approval to shorten the period from four months to three and one-half months, changing from November 1 to February 29 to November 1 to February 15. New York City (NY-CT-NJ) changed from October 1 to April 30 to November 1 to February 29 period. In contrast, El Paso lengthened the period from November 1 to February 29 to October 1 to March 31. Similarly, Phoenix, Arizona changed from October 1 to February 29 to November 15 to March 31. Minneapolis and St. Paul, Minnesota changed from 
October 1 to January 31 to year around (January 1 to December 31$)^{49}$ (EIA, 1998). From 1994 through April 1996, twenty-two cities were re-designated as CO attainment areas. However, as of March 28, 1999, cities that have been designated or redesignated as "serious" CO non-attainment areas include Denver/Boulder, Las Vegas, Phoenix, Los Angeles, Fairbanks, Anchorage, and Spokane (EPA 1999).

Some areas have also changed the specific oxygenate requirement of minimum $2.7 \%$ in weight, which is equivalent to $7.7 \%$ ethanol in volume. Spokane, Washington requires $3.5 \%$. Anchorage, Alaska specifically requires $10 \%$ ethanol in volume. and Las Vegas, Nevada, and Phoenix, Arizona require 3.5\% oxygen in weight. Denver, Colorado, and Provo-Orem, Utah requires an average of $3.1 \mathrm{wt}$. \% oxygen. On the other hand, California limits the maximum oxygen content to $1.8-2.2 \mathrm{wt}$ \% (EIA, 1998).

The winter oxygenate requirement potentially increased the demand for ethanol and other oxygenates, compared to the situation without such a requirement. This potential demand increase would be higher the higher the wt. or vol. \% of ethanol utilized; the longer the control period; and the more explicit the requirement for using ethanol as the oxygenate. For example, as of March 29, 1999, 100\% of the oxygenate in ten of 19 areas is ethanol: Minneapolis/St. Paul, El Paso, Missoula, Las Vegas, Reno, Grants Pass, Klamath Co., Medford, Anchorage, and Spokane. 95\% of the oxygenate in Phoenix is ethanol; $80 \%$ is ethanol in Provo/Orem; and 75\% is ethanol in the three Colorado areas of Colorado Springs, Denver/Boulder, and Ft. Collins. In contrast, the oxygenate is $100 \%$ MTBE in Los Angeles and 80\% MTBE in New York/Northern NJ/Connecticut (EPA 1999).

\section{EPA Health Effects Testing}

Since the 1978 waiver was granted, EPA promulgated regulations pertaining to health effects testing, (see 40 CFR Part 79). Sections 211 (b) (2) and 211(e) of the Clean Air Act authorize EPA to establish requirements for the registration of designated fuels and fuel additives. Industry is required to keep registrations current for each fuel or fuel additive to introduce the product into commerce.

The registration requirements are organized within a three-tier structure. Tier 1 requires manufacturers to perform a literature search on the health effects of the fuel or fuel additive in question and requires a characterization of the emissions. The emission characterization required is extensive. In addition to the basic emissions of $\mathrm{CO}, \mathrm{THC}$, $\mathrm{NO}_{\mathrm{x}}$, and particulates, specification of volatile HCs, aldehydes, ketones, alcohols, ethers, polycyclic (i.e., two or more usually fused rings in a molecule) aromatic compounds, and atypical emission products must be specified. Limited (i.e., qualitative) exposure information is also required. Tier 2 requires biological testing to examine subchronic systemic and organ toxicity to review carcinogenicity, mutagenicity, teratogenicity, reproductive toxicity, and neurotoxicity. When necessary, EPA may request additional testing under Tier 3.

\footnotetext{
${ }^{49}$ As will be noted later, this is also changed to a statewide requirement.
} 
The health effects regulations also contain a provision entitled "Alternative Tier 2." The Alternative Tier 2 provision applies to fuels and fuel additives for which EPA has chosen to modify the standard Tier 2 requirements. The exercise of this authority is at EPA's discretion and is intended to provide flexibility when a different testing regime is preferable to standard Tier 2 tests.

Alternative Tier 2 provisions apply when one or several of three circumstances exist: (1) Information may be available concerning a fuel or fuel additive that causes particular concern. Alternative 2 provisions allow EPA to require specific information earlier in the process even if ordinarily not required in Tier 2 testing; (2) Previously submitted Tier I information may identify a potentially significant health risk where EPA has definitively identified the need for additional testing; and (3) EPA may identify concerns about the effects of fuels or fuel additives on different engines ordinarily used and tested in Tier 2 evaluations. In short, the alternative Tier 2 provisions give EPA the flexibility to prescribe additional tests in addition to the standard Tier 2 provisions, to substitute different tests, and to modify the underlying vehicle/engine specifications for Tier 2.

In ethanol's case, Alternative Tier 2 testing has been initiated to assess the health effects of the primary oxygenates used in U.S. gasoline. (Sopata 1999). Those oxygenates include $10 \%$ ethanol blends, methyl tertiary butyl ether (MTBE) blends, tertiary butyl alcohol (TBA), ethyl tertiary butyl ether (ETBE) blends, di-iso-propyl ether (DIPE) blends, and tertiary amyl methyl ether (TAME) blends.

The key issue cited by EPA is whether ethanol will be able to meet the $\mathrm{NO}_{\mathrm{x}}$ standard required by the Light Duty Vehicle Emission Standards, (as required by Section 211 (f) of the "substantially similar" provisions.) (Broffie 1999). The standards are as follow:

$\begin{array}{ll}\text { Total HC } & 0.41 \\ \mathrm{CO} & 3.4 \\ \mathrm{NO}_{\mathrm{x}} & 0.4\end{array}$

The applicability of the Alternative Tier 2 review to higher ethanol blends is in part determined by the annual revenue generated by the higher ethanol blend producer. If the producer generates annual revenue of greater than $\$ 50$ million, that producer is subject to an Alternative Tier 2 evaluation prior to introducing higher ethanol blends into commerce. On the other hand, if the producer generates less than $\$ 50$ million revenue annually, higher ethanol blends could be introduced into the marketplace without first being subject to an Alternative Tier 2 review. Either case assumes that EPA first granted a new waiver for higher ethanol blends under "substantially similar" provisions (Broffie, Caldwell 1999). 


\section{Federal Replacement Fuels Requirements}

In implementing these and related provisions in EPAct, DOE has been coordinating the Federal Fleet Program for purchasing alternative fuel vehicles (AFVs) in the federal fleets. DOE has also instituted the Clean Cities Program to promote voluntary commitments and actions by key groups in participating cities to install alternative fuel infrastructure and to buy AFVs (U.S. DOE, 1997). Among the AFVs are E85 (85\% ethanol and 15\% gasoline) and E95 (95\% ethanol and 5\% gasoline) vehicles. E85 vehicles are light-duty cars and trucks, while E95 vehicles are heavy-duty vehicles.

Both the Federal Fleet and the Clean Cities Programs promote E85 vehicles in addition to other AFVs. Estimates and projections by the Energy Information Administration of numbers of ethanol vehicles and corresponding consumption are shown below:

- E85 vehicles increased from 172 in 1992 to 9,389 in 1997, and 10,872 in 1998.

- E95 vehicles increased from 38 in 1992 to 357 in 1997 and $1998 .^{50}$

Correspondingly, consumption of ethanol-based fuels are estimated as follows:

- Consumption of E85 increased from 21,000 gasoline-equivalent gallons (GEG) in 1992 to 1,416,000 GEG in 1997, and 1,614,000 GEG in 1998.

- Consumption of E95 rose from 85,000 GEG in 1992 to 2,628,000 in 1997 and 1998.

- Ethanol used as oxygenate rose from 701,000,000 GEG to 787,800,000 GEG in 1997, and $852,500,000$ GEG in $1998 .^{51}$

With respect to the EPAct section 502(b)(2) replacement and alternative fuel goals, DOE has concluded from its analysis that the $30 \%$ goal for 2010 "could be sustainable based on underlying economics if the transitional impediments could be overcome." However, reaching the goal of $30 \%$ replacement fuel use would entail a very steep ramp of AFV purchases from the present through 2010. The AFV purchases required by the EPAct fleet mandates would barely begin the progression toward these goals. The degree of spillover from the fleet AFV use into household use is very uncertain but will almost certainly be determined by perceived economic advantages/disadvantages of the different fuels; current prices and tax structures do not appear to favor substantial spillover. A smoother progression of AFV sales could reach the $30 \%$ goal but probably not before 2020 (U.S. DOE, 1997, p.1).

\footnotetext{
${ }^{50}$ Energy Information Administration. (1997). Alternatives to Traditional Transportation Fuels, 1996. Table 1. 1997 values are preliminary, while 1998 values are projected.

${ }^{51}$ Energy Information Administration, 1997, Table 10. 1997 values are preliminary, while 1998 values are projected. However, production data released by the Renewable Fuels Association indicates by October 1998, actual production of ethanol reached 1.36 billion gallons (Renewable Fuels Association, Press

Release, December 1, 1998). This would suggest that the EIA projection for 1998 is lower than actual.
} 


\section{Federal Alternative Fuels Promotion Act}

In May 1999, Senators John D. Rockefeller IV, Mike Crapo, and Richard Bryan proposed the Alternative Fuels Promotion Act. It contains four provisions: (1) It increases the maximum electric vehicle tax credit from $\$ 4,000$ to $\$ 5,000$ or $10 \%$ of purchase price and extends the sunset date of the credit to 2010. (2) The bill gives a tax deduction of up to $\$ 30,000$ for the cost of installing alternative fueling stations. This is in addition to the tax deduction of $\$ 100,000$ for the cost of capital equipment associated with installing alternative fueling stations. (3) It gives a $\$ 0.50$ per gasoline-equivalent gallon tax credit to the sellers of clean-burning alternative fuels used in alternative fuel vehicles. For this provision, the alternative fuel definition does not include ethanol, as other tax credits already apply to ethanol. As such, the proposed bill would balance the tax basis for all alternative fuels. (4) It would give states the authority to allow single occupant, alternative fuel vehicles in high occupancy vehicle (HOV) lanes.

Thus, Provision (2) would potentially encourage businesses and investors to develop alternative fueling stations, including those for ethanol fuels, making it more available and convenient for refueling. Provision (4) makes it permissible for states to accord alternative fuel vehicles a special status and thus encourage consumers to purchase such vehicles, including those fueled by ethanol-blended fuels. However, Provisions (1) and (3) improve the comparative advantages of alternative fuels that compete with ethanol blended fuel, and could potentially alter the market climate in which higher ethanol blends could apply.

\section{State Oxygenate Requirements}

\section{California}

In 1991, the CARB adopted the winter oxygenate rule to comply with the federal requirements originating from CAAA. However, because of concern about the adverse impacts of higher levels of oxygenates on $\mathrm{NO}_{\mathrm{x}}, \mathrm{CARB}$ requested and obtained a waiver from EPA on the $2.7 \mathrm{wt}$. \% oxygen requirement in the wintertime oxygen requirements. Instead, CARB adopted a requirement for 1.8 to $2.2 \mathrm{wt}$. \% oxygen, predicated upon the provision that $\mathrm{NO}_{\mathrm{x}}$ emissions would not significantly increase. At the time, about $80 \%$ of gasoline used in California was in the $\mathrm{CO}$ non-attainment areas. As a result, the wintertime oxygenates requirement was applied statewide. Extending the wintertime oxygenates rule from the $\mathrm{CO}$ non-attainment areas to the entire state potentially increased the demand for ethanol by $25 \%$.

\section{Other Select States}

In Minnesota, the Twin Cities (Minneapolis and St. Paul) metropolitan area is a federally designated wintertime CO non-attainment area. During the period from October 1 to January 31 , gasoline sold in the region must contain $2.7 \%$ oxygen by weight, which is equivalent to $7.7 \%$ ethanol by volume. In 1991, Minnesota enacted a year-round 
requirement that gasoline used for motor fuel must have $2.7 \mathrm{wt}$ \% oxygen content. This requirement went into effect in the Twin Cities area in October 1995. It became effective statewide in October 1997. (Minnesota Office of Legislative Auditor 1997, p. 4). Currently, EPA is working on a session to the states implementation plan to redesignate the Minneapolis and St. Paul area to CO attainment (EPA, 1999).

Minnesota's ethanol programs have included a producer payment (20 cents a gallon), blender's tax credits, subsidized loans to ethanol producers, and other grants and tax increment financing. The producer payment started in 1986, and payments and maximum limits have been increased over time from 15 cents per gallon to 20 cents per gallon. The blender's credit was 20 cents per gallon (of pure ethanol) until October 1994; 15 cents per gallon until October 1995; and 5 cents per gallon until October 1997. There are two loan programs administered by the Minnesota Department of Agriculture. The Ethanol Production Facility Loan Program helps finance ethanol plants with low-interest loans of up to $\$ 500,000$ with a 7 to 10 year term. The Value-Added Agriculture Product Loan Program helps to finance the purchase of stock in various farmer-owned cooperatives, including ethanol plants. The loans provide $45 \%$ of the loan principal to a maximum of $\$ 24,000$ to farmers applying for a loan through local lenders. Some ethanol also qualified for economic recovery grants administered by the Department of Trade and Economic Development, and tax increment financing up to $\$ 1.5$ million. (Minnesota Office of the Legislative Auditor, 1997, pp. 4-7.)

\section{State/Municipal Reformulated Gasoline Requirements}

\section{California}

In 1991, CARB determined that the Federal reformulated gasoline would not provide sufficient clean-air benefits to enable California to attain the federal ozone standards. CARB then specified its own set of clean-fuel requirements (CaRFG). Phase 3 regulations were finalized on September 2, 2000, with an implementation/compliance date of December 31, 2002. Phase 3 requirements address RVP, sulfur, benzene, aromatic hydrocarbons, HCs, olefins, oxygen, T90, and T50 parameters.

In 1998, two key amendments with implications for the adoption and use of E17-E24 were adopted by CARB. These amendments were geared toward giving refiners more options on oxygen content and providing them with more flexibility in meeting the CaRFG requirements. First, on August 27, 1998, the Board voted to eliminate the requirement for a minimum of $1.8 \mathrm{wt} . \%$ oxygen in winter gasoline for the areas in the state which had been re-designated as $\mathrm{CO}$ attainment areas. In areas not subject to the year-round federal oxygenate requirement, refiners now can use the California Predictive Model to reduce or eliminate the oxygen content in their gasoline year round, which could have a potentially negative effect on demand for ethanol as an oxygenate.

Second, on December 11, 1998, the CARB amended the requirement of maximum oxygen content "cap" limit, raising it from 2.7 to $3.5 \mathrm{wt} . \%$. This change allows refiners and blenders to produce RFG with 10 vol. \% ethanol. At the same time, the CARB determined 
that a 10 vol. \% ethanol blend with 1 psi higher RVP will lead to increased ozone forming potential than a fully complying blend of RFG. In essence, refiners and blenders, in formulating a 10 vol. \% ethanol blend of fuels, still need to meet the RVP requirement ( 7 psi) of Phase 2 and 3 of the CaRFG program.

However, in announcing the decision, CARB also encouraged staff to "work with the ethanol industry to find new ways to utilize ethanol" in the clean-burning gasoline program. CARB further indicated that, in 1999, staff would undertake a comprehensive review of the clean-burning gasoline program to identify opportunities to provide greater flexibility of oxygenates use. ${ }^{52}$ According to the Renewable Fuels Association (RFA), CARB recognized the "growing consensus that some RVP flexibility is warranted" and directed "staff to work with the ethanol industry and evaluate the degree to which ethanol's reduced reactivity and lower CO emissions can be used to offset some level of RVP." The RFA also stated that representatives of the oil industry had expressed support for such a collaborative approach. ${ }^{53}$ Developments and events in this area bear monitoring because they can have important implications for the ethanol market.

\section{Select Other States/Municipalities}

The Arizona requirement for reformulated gasoline has two components. (1) From and after May 1, 1999, gasoline sold in the greater Phoenix area (Maricopa county) can comply with either the Federal Phase II RFG requirements or the California Phase 2 RFG, ${ }^{54}$ subject to the Arizona maximum vapor pressure of 9 psi from September 30 through March 31 and 7 psi from May 31 through September 30 of each year. (2) Specifically for winter months for the greater Phoenix area (Maricopa county), the requirements for RFG combine the California Phase 2 reformulated gasoline requirements (including alternative formulations allowed by the California Predictive Model) with the mandatory requirement of "not less than $10 \%$ by volume of ethanol." The winter months are defined as November 1, 2000 through March 31, 2001, and each year thereafter. (House Bill 2347, enacted in May 1998, has been codified in Arizona Revised Statute 41-2124 and 41-2123.)

A similar requirement to use ethanol in oxygenated gasoline for ozone non-attainment areas occurred at the local government level in Anchorage, Alaska. As mentioned above, Anchorage's oxygenated gasoline program went into effect on November 1, 1992, but was suspended by the Governor in December 1992 because of concerns about the health effect of MTBE in the blended gasoline. On July 12, 1994, the City of Anchorage passed a resolution calling for the use of ethanol-blended gasoline as a transportation control measure. The resolution requested that the State of Alaska "enact regulations which require the use of gasoline with ethanol fuel in Anchorage, as a locally selected Transportation

\footnotetext{
${ }^{52}$ See CARB, “ARB Increases Allowable Amount of Ethanol in California Gasoline," News Release, 9877, December 11, 1998.

${ }^{53}$ See Renewable Fuels Association, Ethanol Report. Issue \#85, December 21, 1998, pp.1-2.

${ }_{55}^{54}$ Including alternative formulations allowed by the California Predictive Model.

${ }^{55}$ According to Michelle Ringsmuth of Arizona Department of Environmental Quality, California RFG Phase II's requirement of benzene and toxics are also not included in the Arizona requirements. Telephone conversation on April 15, 1999.
} 
Control Measure to achieve compliance with the Federal Clean Air Act, to be implemented no later than January 1, 1995." (Anchorage General Assembly, 1994) Note that the state oxygenated gasoline requirements for Alaska per se, as stated in Article 1 of Title 18 Environmental Conservation, Chapter 53, Fuel Requirements for Motor Vehicles (8 AAC 53), are neutral in terms of specific oxygenates. The requirement to use ethanol in oxygenated gasoline was imposed by the municipality (Shepard 1999). 


\section{REPORT DOCUMENTATION PAGE}

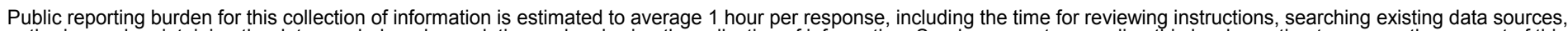

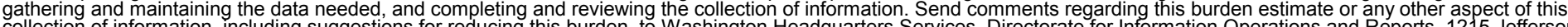

Davis Highway, Suite 1204, Arlington, VA 22202-4302, and to the Office of Management and Budget, Paperwork Reduction Project (0704-0188), Washington, DC 20503.
1. AGENCY USE ONLY (Leave blank)
2. REPORT DATE
September 2002
3. REPORT TYPE AND DATES COVERED
Technical Report

\section{TITLE AND SUBTITLE}

Issues Associated with the Use of Higher Ethanol Blends (E17-E24)

6. $\operatorname{AUTHOR}(\mathrm{S})$

C. Hammel-Smith, J. Fang, M. Powders, and J. Aabakken

7. PERFORMING ORGANIZATION NAME(S) AND ADDRESS(ES)

8. PERFORMING ORGANIZATION

REPORT NUMBER

5. FUNDING NUMBERS

\section{BFP2.A101}

9. SPONSORING/MONITORING AGENCY NAME(S) AND ADDRESS(ES)

National Renewable Energy Laboratory

1617 Cole Blvd.

Golden, CO 80401-3393

10. SPONSORING/MONITORING AGENCY REPORT NUMBER

NREL/TP-510-32206

11. SUPPLEMENTARY NOTES

12a. DISTRIBUTION/AVAILABILITY STATEMENT National Technical Information Service

12b. DISTRIBUTION CODE

U.S. Department of Commerce

5285 Port Royal Road

Springfield, VA 22161

13. ABSTRACT (Maximum 200 words)

This report reviews the issues associated with utilizing higher ethanol blends (E17-E24) and is intended to advise the

Department of Energy on factors that might encourage or constrain the integration of such blends into the marketplace.

14. SUBJECT TERMS

15. NUMBER OF PAGES

ethanol; ethanol blends; E17; E24

16. PRICE CODE

17. SECURITY CLASSIFICATION OF REPORT Unclassified
18. SECURITY CLASSIFICATION OF THIS PAGE Unclassified
19. SECURITY CLASSIFICATION OF ABSTRACT Unclassified
20. LIMITATION OF ABSTRACT

UL 